\title{
Adsorptive Removal of Manganese lons From Polluted Aqueous Media by Glauconite Clay- Functionalized Chitosan Nanocomposites: Adsorption, Kinetic, Isotherm, and Thermodynamic Investigations
}

Mostafa Y Nassar ( $\nabla$ m_y_nassar@yahoo.com )

Ain Shams University https://orcid.org/0000-0002-5177-9777

Marwa M. Sobeih

Ain Shams University

M.F. El-Shahat

Ain Shams University

\section{A. Osman}

Ain Shams University

M. A. Zaid

Ain Shams University

\section{Research Article}

Keywords: Manganese ions, adsorptive removal, glauconite clay, functionalized chitosan nanocomposite

Posted Date: March 22nd, 2021

DOI: https://doi.org/10.21203/rs.3.rs-322618/v1

License: (c) (i) This work is licensed under a Creative Commons Attribution 4.0 International License.

Read Full License 


15

Adsorptive removal of manganese ions from polluted aqueous media by glauconite clayfunctionalized chitosan nanocomposites: Adsorption, kinetic, isotherm, and thermodynamic investigations

\author{
Marwa M. Sobeih ${ }^{1,2}$, M.F. El-Shahat ${ }^{1 *}$, A. Osman ${ }^{3}$, M. A. Zaid ${ }^{2}$, Mostafa Y. Nassar ${ }^{4 *}$ \\ ${ }^{\mathbf{1} C h e m i s t r y ~ D e p a r t m e n t, ~ F a c u l t y ~ o f ~ S c i e n c e, ~ A i n ~ S h a m s ~ U n i v e r s i t y, ~ C a i r o, ~ E g y p t ~}$ \\ ${ }^{2}$ Abu-Zaabal Company for Fertilizer and Chemical Company (AZFC), EL-Qalyubia, Egypt \\ ${ }^{3}$ Geology Department, Faculty of Science, Ain Shams University, Cairo, Egypt \\ ${ }^{4}$ Chemistry Department, Faculty of Science, Benha University, Benha 13815, Egypt
}

*Corresponding authors: E-mail address: m_y_nassar@yahoo.com, m_y_nassar@fsc.bu.edu.eg. Tel.: +20 1068727555 (M.Y. Nassar). elshahatmf@ hotmail.com, Tel.: +20 1128323115 (M.F. El-Shahat). Marwa_Sobeih1@ yahoo.com, Tel.: +01093279991 (M.M. Sobeih).

\title{
Abstract
}

The presence of $\mathrm{Mn}(\mathrm{II})$ in water exceeding the permitted concentration declared by the World Health Organization (WHO) influences individuals, animals, and the ecosystem negatively. Therefore, there is a necessity for an efficient material to eliminate this potentially toxic element from wastewater. We herein focused on an adsorptive removal of $\mathrm{Mn}(\mathrm{II})$ ions from polluted aqueous media using natural Egyptian glauconite clay $(\mathrm{G})$ and its nanocomposites with a modified chitosan (CS). The applied chitosan was modified with glutaraldehyde (GL), ethylenediaminetetraacetic acid (EDTA), sodium dodecyl sulfate (SDS) and cetyltrimethyl 
24 ammonium bromide (CTAB). The utilized nanocomposites were referred to as GL-CS/G, EDTA-

25 GL-CS/G, SDS-CS/G, and CTAB-CS/G, respectively. The points of zero charge values of the as-

26 prepared materials were estimated. The adsorption properties of the $\mathrm{G}$ clay and its nanocomposites

27 toward the removal of $\mathrm{Mn}(\mathrm{II})$ ions from polluted aqueous media as well as the adsorption

28 mechanism were explored using a batch technique. The glauconite $(\mathrm{G})$ and its nanocomposites:

29 GL-CS/G, CTAB-CS/G, EDTA-GL-CS/G, and SDS-CS/G, exhibited maximum adsorption 30 capacity values of $3.750,24.11,26.25,27.15$, and $27.74 \mathrm{mgg}^{-1}$, respectively. The adsorption results

31 fitted well the Langmuir isotherm and pseudo-second-order kinetic models. The determined

32 thermodynamic parameters revealed that the $\mathrm{Mn}(\mathrm{II})$ ion adsorption process was endothermic,

33 spontaneous, and physisorption controlled. Furthermore, the obtained adsorption results are

34 encouraging and revealing a great potentiality for using the modified adsorbents as accessible

35 adsorbents for $\mathrm{Mn}(\mathrm{II})$ ions removal from polluted aqueous solutions, depending on their

36 reusability, high stability and good adsorption capacities.

Keywords: Manganese ions; adsorptive removal; glauconite clay; functionalized chitosan

39 nanocomposite.

40

\section{1- Introduction}

Heavy metals are considered one of the main sources of industrial wastewater pollution,

43 which seriously menace the human health and the biological environment. It is necessary to

44 remove the inorganic pollutants from wastewater before being discharged into the environment

45 due to their high stability and non-degradable nature $(1,2)$. Although some heavy metals such as

46 manganese, copper, iron, and zinc are essential for human health under particular concentrations,

47 but above these concentrations they become toxic and cause various health problems (3). Water 
contamination with heavy metals such as manganese is a problematic problem, and it has attracted

49 significant interest from many research groups $(3,4)$. Manganese is one of those inorganic

50 pollutants present in aquatic environment. It has three possible oxidation states, namely $\mathrm{Mn}(\mathrm{II})$,

$51 \mathrm{Mn}(\mathrm{III})$ and $\mathrm{Mn}(\mathrm{IV})$. The Mn(II) ion is the only form that is stable in soil solution, whereas

$52 \mathrm{Mn}(\mathrm{III})$ and $\mathrm{Mn}(\mathrm{IV})$ forms are only stable in the solid phase. The divalent manganese (Mn(II)) is

53 discharged via the wastewaters of ceramics, battery, electrical coils, glass, leather, and textile

54 industries (5). As mentioned before, trace amounts of manganese ions are useful for human body,

55 since they act as an activator for some enzymes (6). However, high concentrations of manganese

56 ions can cause various health diseases such as cells mutation, damage of central nervous systems,

57 weakness, lack of fertility, acute intoxication, permanent disabilityand paralysis (7).Therefore,

58 the recommended levels permitted for manganese concentrations are $0.05 \mathrm{mgL}^{-1}$ in drinking

59 water and $5.0 \mathrm{mg} / \mathrm{L}$ in surface water according to the drinking water quality standard and the

60 recommendations of USEPA (8). Hence, the removal of Mn(II) ions from wastewater is

61 necessary for human and environmental safety.

To date, different techniques have been developed for manganese ions removal from 63 aqueous solutions such as ion-exchange, precipitation, membrane filtration, bio- degradation, 64 solvent extraction, and advanced oxidation, and adsorption (9). However, due to simplicity, high 65 efficiency, low-cost and wide adaptability of the adsorption process, it still has the superiority 66 among other techniques $(10,11)$. In this context, various adsorbent materials, including clay

67 minerals, natural and prepared polymers, activated carbons, zeolites, and agricultural byproducts

68 have been used for manganese ions removal from wastewater (12). use of clays as adsorbent to remove $\mathrm{Mn}(\mathrm{II})$ from water has great advantages compared with other commercial adsorbents in 70 terms of high specific surface area, low-cost, high adsorption properties, availability, non-toxicity 
71 and large potential for ion exchange (13). In this light,one of natural clay minerals known as

72 glauconite clay $(\mathrm{G})$ was selected for $\mathrm{Mn}(\mathrm{II})$ ions adsorption. Glauconite like other clay mineral

73 characterized by chemical and mechanical stability, layered structure, large surface area as well

74 as high thermal stability and little electrical conductivity due to the existence of metal oxides in

75 its composition (14). Its structure is classified as 2:1 type with presence of one octahedral sheet

76 sandwiched by two tetrahedral sheets (15). It has a chemical formula of (K, $\mathrm{Na})(\mathrm{Fe}, \mathrm{Al}, \mathrm{Mg})_{2}$

$77(\mathrm{Si}, \mathrm{Al})_{4} \mathrm{O}_{10}(\mathrm{OH})_{2}$, with presence of two types of iron $\left(\mathrm{Fe}^{2+}\right.$ and $\left.\mathrm{Fe}^{3+}\right)$ ions. The content of

$78 \mathrm{Fe}^{3+}$ cations may be accountable for its properties as it is usually found in an amount greater than

$79 \mathrm{Fe}^{2+}(16)$. Despite, $\mathrm{G}$ exhibits strong adsorption property that can be employed as cation

80 exchanger and as an effective absorber in water and oil products (16), it have poor sedimentation

81 properties, which can be overcome by using coagulants or applying a relatively long stability

82 time, which in turn considered an additional cost of the overall operation (17). Therefore, various

83 modification process chemical or physical can be undertaken for improving their removal

84 efficiency (18).

Recently, the modification of clays by natural or synthetic polymers has gained critical

86 research interest producing new compounds containing both organic and inorganic ingredients

87 with distinguishable interface and diverse chemical and physical characteristics, such as corrosion

88 resistance, low density, thermal isolation, high hardiness and flame retardants (19). Among all the

89 most common polymers, chitosan is the second-most abundant natural biopolymer with distinct

90 advantages. Chitosan gained interest of scientists not only owing to it's astonishing properties like

91 local availability, biocompatibility, biodegradability, non-toxicity, low cost, bioactivity, attractive

92 physical and mechanical properties, besides a presence of large number of amine and hydroxyl

93 functional groups (20), but also due to its simplicity for development as a multifunctional 
94 adsorbent depending upon the applied field. Chitosan is a cationic polymer resulting from N95 deacetylation of chitin in alkaline medium (21). Due to the solubility of chitosan in dilute mineral 96 acids, its chemical stability should be enhanced by special modification. Most of these methods

97 are done using functional crosslinking agents, which unfortunately can reduce the efficiency of 98 chitosan uptake due to the participation of amino groups in the crosslinking procedure. Therefore, 99 the interpolation of special functional crosslinking agents known for their high performance such 100 as ethylene-di amine tetra acetic acid (EDTA) (22), and ionic surfactants like cetyltrimethyl101 ammonium bromide (CTAB) and sodium dodecyl sulfate (SDS) $(23,24)$ is an influential 102 modification method to reinforce their adsorption capacity and selectivity. Accordingly, we have 103 recently reported a new simple approach for fabrication of some nanocomposites such as cross104 linked chitosan/glauconite clay, EDTA-chitosan modified glauconite, CTAB-modified 105 chitosan/glauconite, and SDS-modified chitosan/glauconite composites. These prepared 106 nanocomposites showed high efficiency in removing fluoride ions from wastewater. On the other 107 hand, due to the high toxicity of $\mathrm{Mn}(\mathrm{II})$ ions at higher concentrations and the various functional 108 groups that the as-prepared nanocomposites have, we herein report on the removal of $\mathrm{Mn}$ (II) ions 109 from polluted water utilizing the aforementioned nanocomposites. Various influencing factors on 110 the adsorption process have been examined such as initial $\mathrm{pH}$, contact time, dosage, etc. The 111 experimental data were examined using different isotherm models. The kinetics and 112 thermodynamics of the adsorption process were also estimated. Also, regeneration of the prepared 113 adsorbents was investigated in this study.

\section{2. Experimental}

\subsection{Materials and reagents}


Raw Glauconite clay $(\mathrm{G})$ with chemical content of $\mathrm{SiO}_{2}: 50.50 \%, \mathrm{Fe}_{2} \mathrm{O}_{3}: 20.88 \%, \mathrm{Al}_{2} \mathrm{O}_{3}$ :

$7.88 \%, \mathrm{~K}_{2} \mathrm{O}: 5.00 \%, \mathrm{MgO}: 2.81 \%, \mathrm{CaO}: 0.34 \%, \mathrm{SO}_{3}: 1.2 \%$ and $\mathrm{Na}_{2} \mathrm{O}: 0.95 \%$ was collected from El-Gideda area, Egypt. Chitosan (CS) (Deacetylation degree $>85 \%$ ), cetyltrimethyl ammonium bromide (CTAB), and sodium dodecyl sulfate (SDS) were purchased from Sigma Chemical Co., USA. All other chemicals were of analytical grade e.g. acetic acid; sodium hydroxide, $\mathrm{HCl}$, and glutaraldehyde (GL) also were used without further purification as received from El-Nasr Pharmaceutical Chemicals Company (ADWIC)-Company, Egypt. The standard solutions of manganese ion was prepared by dilutions of stock solution $\left(1000 \mathrm{mgL}^{-1}\right)$, which were purchased from Merck. $\mathrm{pH}$ value of the adsorption media was adjusted when required using $0.2 \mathrm{~N} \mathrm{HCl}$ and/or $\mathrm{NaOH}$ solutions. De-ionized water was used for all preparations.

\subsection{Adsorbent preparation}

The preparation methods of glauconite clay $(\mathrm{G})$, cross-linked chitosan/glauconite clay (GL-CS/G) composite, EDTA-chitosan modified glauconite (EDTA-GL-CS/G) composite, and surfactant-modified chitosan/glauconite (CTAB-CS/G and SDS-CS/G) composite preparation were reported by our research group elsewhere (25).

\subsection{Materials characterization}

The chemical and mineralogical characterization of the raw glauconite and the as-prepared composites were reported earlier (25). The manganese ion concentration was determined by atomic absorption spectrophotometer (Unicam, Solar 929, UK supplied with acetylene and nitrous oxide burner heads) at $279.5 \mathrm{~nm}$ resonance line according to the reported standard method (26). The $\mathrm{pH}$ value was measured using $\mathrm{pH}$-meter model Sension 3 (Huch, USA). The zero point charge of the adsorbents (pHzpc ) was estimated by the $\mathrm{pH}$ drift method (27) using $0.01 \mathrm{M} \mathrm{NaCl}$ solutions at different $\mathrm{pH}$ values varied between 2 to 10 . 


\subsection{Adsorption studies}

The application of raw glauconite clay and its as-prepared composites as adsorbents for 143 manganese ion removal was explored using batch technique. To study the equilibrium system of 144 adsorption, adsorbent weight of $0.1 \mathrm{~g}$ was taken into intimate contact with manganese solutions $(0.05 \mathrm{~L})$ of different concentrations ranging from 10 to $300 \mathrm{mgL}^{-1}$. The admixtures were magnetically stirred (350 rpm stirring speed) at a temperature of $25^{\circ} \mathrm{C}$, specific $\mathrm{pH}$ value adjusted using $0.2 \mathrm{~N} \mathrm{NaOH}$ or $0.2 \mathrm{~N} \mathrm{HCl}$ solutions and a predetermined time intervals. Then, the adsorbents were filtered and the residual manganese concentration in the filtrate was analyzed by atomic absorption spectrophotometer using a pre-constructed calibration curve for the manganese cation.

The removal efficiency percent $(\% \mathrm{R})$, capacity $\left(\mathrm{q}_{\mathrm{t}}, \mathrm{mgg}^{-1}\right)$, and the equilibrium capacity ( $\mathrm{q}_{\mathrm{e}}$, 151 manganese concentration, and $\mathrm{C}_{\mathrm{e}}\left(\mathrm{mgL}^{-1}\right)$ is the equilibrium manganese concentration at time 0 , $\mathrm{t}$, and equilibrium time, respectively, for the adsorption. While $\mathrm{m}(\mathrm{g})$, and $\mathrm{V}(\mathrm{L})$ are the weight and the volume of adsorbent and solution, respectively.

\section{Results and discussion}

In our earlier studies, we reported on the preparation of glauconite clay $(\mathrm{G})$, cross-linked 162 chitosan/glauconite clay (GL-CS/G), EDTA-chitosan modified glauconite (EDTA-GL-CS/G), and surfactant-modified chitosan/glauconite (CTAB-CS/G and SDS-CS/G) composites (2). We also 
164 reported previously on the characterization of these materials using different techniques including

165 Fourier-transform infrared spectroscopy (FTIR), X-ray diffraction (XRD), field emission scanning 166 electron microscopy (FE-SEM), nitrogen physical adsorption (BET), atomic absorption 167 spectrophotometry (AA), and thermal gravimetric analysis (TGA). Additionally, these 168 nanocomposites were used in that previous work for the removal of fluoride ions from aqueous 169 solutions. In the present study, as a continuation to our research, we have applied the 170 aforementioned nanocomposites as adsorbents for the removal of manganese(II) ions from 171 aqueous media due to its high toxicity at higher concentrations than the permissible limits (8). 172 However, the point of zero charge (pHpzc) values of these adsorbents have not been reported 173 previously. Due to their importance, we have started our current research by their estimation as 174 will be shortly mentioned. adsorbents

The point of zero charge $\left(\mathrm{pH}_{\mathrm{pzc}}\right)$ value of the adsorbent is essential for a better 179 understanding the adsorption mechanisms; it is well-defined as the $\mathrm{pH}$ value where the adsorbent surface has no charge in specific adsorption. At a $\mathrm{pH}$ higher than $\mathrm{pH}_{\mathrm{pzc}}$; the surface of adsorbents 181 carries a negative charge and thus favors absorption of cations. At a $\mathrm{pH}$ lower than $\mathrm{pH}_{\mathrm{pzc}}$; the 182 adsorbent carries a positive charge and thus prefers the adsorption of anions (22). Values of $\mathrm{pH}_{\mathrm{pzc}}$ 183 were determined by the $\mathrm{pH}$ drift method. In this method, adsorbent suspensions in $0.01 \mathrm{M} \mathrm{NaCl}$ 184 solutions with different initial $\mathrm{pH}$ values (2-10) were used for this assessment. The final $\mathrm{pH}$ $185\left(\mathrm{pH}_{\text {final }}\right)$ values were then plotted against the initial $\mathrm{pH}\left(\mathrm{pH}_{\text {initial }}\right)$ values for each adsorbent, Fig. 1, 186 and from these figures the $\mathrm{pH}_{\mathrm{pzc}}$ values were determined. The $\mathrm{pH}_{\mathrm{pzc}}$ values of $\mathrm{G}, \mathrm{GL}-\mathrm{CS} / \mathrm{G}, \mathrm{EDTA}-$ 
187 GL-CS/G, SDS-CS/G, and CTAB-CS/G products were found to be $6.40,5.72,5.88,5.78$, and 188 5.61, respectively. Variation in $\mathrm{pH}_{\mathrm{pzc}}$ of adsorbents in this study may be due to the structural 189 changes during the modification process. These results indicate that the performed $\mathrm{G}$ clay 190 modification has a significant effect on its particle charges which may in turn has a positive impact 191 on the adsorption efficiency toward the manganese cations.

$<$ Fig. (1) >

195

\subsection{Adsorption studies}

Adsorption properties of G, GL-CS/G, EDTA-GL-CS/G, SDS-CS/G and CTAB-CS/G adsorbents were explored using $\mathrm{Mn}(\mathrm{II})$ ions as an adsorbate model. Therefore, several parameters influencing the adsorption process such as $\mathrm{pH}$, contact time, adsorbent dosage, initial $\mathrm{Mn}$ (II) ion concentration, and temperature were studied.

\section{2.1. Effect of $\mathrm{pH}$}

The influence of $\mathrm{pH}$ on the $\mathrm{Mn}(\mathrm{II})$ ion adsorption using $\mathrm{G}, \mathrm{GL}-\mathrm{CS} / \mathrm{G}$, EDTA-GL-CS/G,

204 SDS-CS/G, and CTAB-CS/G adsorbents was examined in the $\mathrm{pH}$ range of 2-7. For this experiment

205 the adsorption working conditions were: $50 \mathrm{mgL}^{-1}$ initial $\mathrm{Mn}(\mathrm{II})$ ion concentration $\left(\mathrm{C}_{0}\right), 1 \mathrm{~g}$ for $\mathrm{G}$ 206 adsorbent and $0.1 \mathrm{~g}$ for GL-CS/G, EDTA-GL-CS/G, SDS-CS/G, and CTAB-CS/G adsorbents, 207 separately, $24 \mathrm{~h}$ contact time, and $25{ }^{\circ} \mathrm{C}$ temperature. The results as displayed in Fig. 2 revealed 208 that the adsorption amount of $\mathrm{Mn}$ (II) ion increased with increasing the initial $\mathrm{pH}$ value until it 209 reached equilibrium at $\mathrm{pH}$ 6.5. Afterward, the precipitation of metal ion hydroxides takes place. 
210 This behavior can be interpreted on the basis of the point of zero charge. Consequently, at acidic

$211 \mathrm{pH}$ values (i.e. $\mathrm{pH}<6.4$ ), the $\mathrm{Mn}(\mathrm{II})$ ion adsorption was low due to the competition between two

212 positively charged $\mathrm{H}^{+}$and $\mathrm{Mn}$ (II) ions for the adsorption sites, and thus, the net interaction is an

213 electrostatic repulsion, which resulting in reduction of $\mathrm{Mn}(\mathrm{II})$ ion adsorption (28). With a gradual

214 rise in $\mathrm{pH}$ value until 6.5 , linked $\mathrm{H}^{+}$is released from the active sites leaving more vacant sites for

215 more $\mathrm{Mn}(\mathrm{II})$ ion adsorption. Beside, this $\mathrm{pH}$ value extent is close to the $\mathrm{pH}_{\mathrm{pzc}}$ at which the surface

216 of clay is surrounded by $\mathrm{OH}^{-}$ions and become negatively charged which in turn attract more

217 positively charged $\mathrm{Mn}(\mathrm{II})$ ion due to the electrostatic attraction (29). With increasing the $\mathrm{pH}$ value

218 toward more basic $\mathrm{pH}$ condition, these active sites are gradually de-protonated and the $\mathrm{Mn}$ (II) ion

219 was hydrolyzed resulting in formation and precipitation of a large number of hydroxides such as

$220 \mathrm{Mn}(\mathrm{OH})^{+}, \mathrm{Mn}_{2}(\mathrm{OH})_{3}, \mathrm{Mn}(\mathrm{OH})_{2}, \mathrm{Mn}_{2}(\mathrm{OH})^{+}{ }_{3}$ and $\mathrm{Mn}(\mathrm{OH})_{4}{ }^{2-}$ species $(30,31)$.

221 On the other hand, the chitosan amino groups in the GL-CS/G, EDTA-GL-CS/G, SDS-CS/G

222 and $\mathrm{CTAB}-\mathrm{CS} / \mathrm{G}$ composites were protonated at lower $\mathrm{pH}$ value and appeared in the form of -

$223 \mathrm{NH}^{3+}$ which in turn increasing the electrostatic repulsion with $\mathrm{Mn}(\mathrm{II})$ ions and resulting in a

224 decline in $\mathrm{Mn}(\mathrm{II})$ ions adsorption. On contrary, with a gradual increase in $\mathrm{pH}$ value, the amino

225 groups are deprotonated and abundant $\mathrm{OH}^{-}$ions created a competitive environment for the

226 adsorption surface sites due to the elctrostatic attraction between positive charged $\mathrm{Mn}$ (II) ion and

227 adsorbents surface sites with negative charge; thus, the increases in removal percent were

228 observed. At a higher $\mathrm{pH}$ value above 6.5, the cumulative effect of $\mathrm{Mn}(\mathrm{II})$ ions adsorption as well

229 as precipitation may be happened. Depending on the above mentioned results, the pH of 6.50 was

230 selected as the optimum $\mathrm{pH}$ value for further adsorption experiments to avoid the interference of

231 results associated with the precipitation of metal ions at higher $\mathrm{pH}$ value. 


\subsubsection{Effect of adsorbent dosage}

The adsorbent dosage is one of the most important factors that affecting the metal ions

237 adsorption due to its effect on the number of binding sites and the total surface area of adsorbent.

238 The effect of adsorbent dosage on the Mn(II) ions removal was studied under the prior operating 239 conditions except the amount of adsorbent. As depicted in Fig. 3(a,b) the removal performance of $240 \mathrm{Mn}(\mathrm{II})$ ions was firstly enhanced until a specific dose of adsorbent, and then reduced as the amount 241 of adsorbent increased. This trend can be attributed to the increase in the adsorptive active sites on 242 the adsorbent surface with the increase in the adsorbent dose up to agiven dose (32), and then the 243 aggregation of the nanoparticles is occurred. This aggregation brought about a reduction in the 244 total available adsorbent surface sites for $\mathrm{Mn}$ (II) ion adsorption, which led to a decrease in the 245 adsorption performance of the adsorbent. These results are consistent with the published data for 246 the adsorption of orange $\mathrm{G}$ textile dye on some nano-adsorbents (33). According to the obtained 247 results, $1 \mathrm{~g}$ of $\mathrm{G}$ and $0.15 \mathrm{~g}$ of GL-CS/G, EDTA-GL-CS/G, SDS-CS/G, and CTAB-CS/G 248 adsorbents were selected as the optimum adsorbent amounts for subsequent studies. The results 249 also exhibited that the adsorption increased in the order of SDS-CS/G > EDTA-GL-CS/G > 250 CTAB-CS/G > GL-CS/G > G. The high removal performance of $\mathrm{Mn}(\mathrm{II})$ ions on SDS-CS/G 251 adsorbent can be ascribed to the interlayer spacing produced from intercalation of $\mathrm{G}$ clay with 252 chitosan polymer as well as the presence of anionic SDS surfactant that changing the G surface 253 from hydrophobic to hydrophilic resulting in a high adsorption of $\mathrm{Mn}$ (II) ion onto both inner and 254 outer adsorbent surface. 


\subsubsection{Effect of contact time}

Effect of adsorption time on $\mathrm{Mn}(\mathrm{II})$ ions removal was investigated over different time intervals (0-300 min) under working conditions: $0.05 \mathrm{~L}$ of $\mathrm{Mn}(\mathrm{II})$ ions solution with $50 \mathrm{mgL}^{-1}$ 261 initial concentration, $25{ }^{\circ} \mathrm{C}$ temperature, pH6.5, $1 \mathrm{~g}$ of $\mathrm{G}$ and $0.15 \mathrm{~g}$ of GL-CS/G, EDTA-GL-

262 CS/G, SDS-CS/G and CTAB-CS/G adsorbents. Fig. 4(a,b) illustrated that the removal of Mn(II) 263 ions was improved by increasing the contact time. The percentage of $\mathrm{Mn}$ (II) ions uptake using 264 the $\mathrm{G}$ adsorbent was initially fast, and then gradually slowed down until reached saturation after 26560 minutes. Hence, for further experiments, 60 minutes was fixed as an optimum contact time for 266 the G adsorbent. On the other hand, GL-CS/G, EDTA-GL-CS/G, SDS-CS/G and CTAB-CS/G 267 composites showed higher adsorption capacities and reached equilibrium after 240 minutes. This 268 contact time was also fixed as the optimum contact time for further experiments, for these 269 composite adsorbents. During the initial stage of adsorption, the rapid uptake is probably due to 270 the availability of the large number of vacant active sites on the adsorbents surface. However, the 271 slow uptake in the later stages are probably generated by less available adsorption active sites, 272 followed by $\mathrm{Mn}(\mathrm{II})$ ions saturation on the surface of adsorbents (34). 

efficiency was examined at different initial Mn(II) concentrations in the range of 10-300 mg/L at $281 \mathrm{pH} 6.5,25^{\circ} \mathrm{C}$, using $1 \mathrm{~g}$ of $\mathrm{G}$ and $0.15 \mathrm{~g}$ of GL-CS/G, EDTA-GL-CS/G, SDS-CS/G and CTAB282 CS/G adsorbents. Fig. 5(a,b) demonstrates that by increasing the initial Mn (II) concentration, the 283 equilibrium adsorption capacity of $\mathrm{Mn}(\mathrm{II})$ was enhanced up to an initial concentration of 200 $284 \mathrm{mg} / \mathrm{L}$ after which a plateau behavior was attained. This behavior can be explained on the basis 285 that increasing the initial $\mathrm{Mn}(\mathrm{II})$ concentration leads to an increased availability of a greater number of $\mathrm{Mn}(\mathrm{II})$ ions at the solid-solution interface, which in turn brings about a higher 287 concentration gradient. Whereas, the constant adsorption capacity observed at an initial metal 288 concentration exceeding $200 \mathrm{mgg}^{-1}$ indicates that all surface active sites having a higher affinity 289 towards Mn(II) ions were saturated. These results are consistent with the published data for the 290 adsorption of manganese on kaolinite clay particles (35).

<Fig. 5. $>$

\subsection{Adsorption kinetics}

To explore the adsorption mechanism and the efficacy of the adsorption process, some 294 kinetic models such aspseudo-first-order, pseudo-second-order, and intra-particle diffusion models. Pseudo-first-order (Eqn. 4) and pseudo-second-order (Eqn. 5) kinetic models are expressed according to the following equations (36-38):

$$
\log \left(q_{e}-q_{t}\right)=\log q_{e}-\frac{k_{1}}{2.303} t
$$

$$
\frac{\mathrm{t}}{\mathrm{q}_{\mathrm{t}}}=\frac{1}{\mathrm{k}_{2} \mathrm{q}_{\mathrm{e}}^{2}}+\frac{1}{\mathrm{q}_{\mathrm{e}}} \mathrm{t}
$$

Where, $\mathrm{q}_{\mathrm{t}}$ and $\mathrm{q}_{\mathrm{e}}\left(\mathrm{mgg}^{-1}\right)$ are the amounts of metal ions adsorbed at time $\mathrm{t}(\mathrm{min})$ and at equilibrium, respectively. $\mathrm{k}_{1}\left(\mathrm{~min}^{-1}\right)$ is the first-order rate constant. Values of $\mathrm{q}_{\mathrm{e}}$ and $\mathrm{k}_{1}$ constants 
302 were determined from the intercept and slope of the plot of $\log \left(\mathrm{q}_{\mathrm{e}}-\mathrm{q}_{\mathrm{t}}\right)$ versus $\mathrm{t}$ (results not shown).

303 The kinetic parameters; $\mathrm{k}_{1}$ and correlation coefficients $\left(\mathrm{r}^{2}\right)$, were listed in Table 1. Additionally, 304 values of $\mathrm{k}_{2}$ and $\mathrm{q}_{\mathrm{e}}$ constants of the pseudo-second-order model can be estimated from the intercept 305 and slope of the linear plot of $t / q_{t}$ versus $t$ (Fig. 6(a)). The parameters; correlation coefficients $\left(r^{2}\right)$ 306 and $\mathrm{k}_{2}$, of the pseudo-second-order model were tabulated in Table 1. By comparison between 307 experimental and calculated pseudo-first-order and pseudo-second-order model values, the results 308 exhibited good fitness of the pseudo-second-order model for the adsorption process of Mn(II) ions. 309 This is due to that the experimentally obtained $\mathrm{q}_{\mathrm{e}(\exp )}$ values from this model are more compatible 310 with the calculated $\mathrm{q}_{\mathrm{e}(\mathrm{cal})}$ ones. Besides, the $\mathrm{r}^{2}$ values from this model were closer to 1 .

311 The data of adsorption was also analyzed using the Weber's intra-particle diffusion model 312 to elucidate the diffusion mechanism. The intra-particle diffusion model (Eqn. (6)) is given as 313 (39):

$$
\mathrm{q}_{\mathrm{t}}=\mathrm{k}_{\mathrm{id}} \mathrm{t}^{0.5}+\mathrm{c}
$$

315 Where $\mathrm{k}_{\mathrm{id}}\left(\left(\mathrm{mgg}^{-1}\right) \mathrm{min}^{-1 / 2}\right)$ is rate constant and $\mathrm{C}\left(\mathrm{mgg}^{-1}\right)$ is the intercept. The larger 316 intercept value, the larger is the surface adsorption contribution in the rate-controlling step. $\mathrm{k}_{\mathrm{id}}$ 317 constant is obtained from the slope of $\mathrm{q}_{\mathrm{t}}$ versus $\mathrm{t}^{1 / 2}$ plot. As displayed in Fig. 6(b), the linear part 318 along the curves of $\mathrm{q}_{\mathrm{t}}$ versus $\mathrm{t}^{1 / 2}$ did not pass through the origin and all of them are multi-linear 319 plots. Therefore, it was concluded that the of $\mathrm{Mn}(\mathrm{II})$ ions adsorption on the $\mathrm{G}$ clay and the as320 prepared composites was complex and controlled not only by the intra-particle diffusion 321 mechanism, but also by various mechanisms such as bulk diffusion and film diffusion mechanisms 322 (40). 


\subsection{Adsorption isotherm studies}

To verify how the metal ions are partitioned between the adsorbents and liquid phases at equilibrium, the adsorption results were examined using some isotherm models such as Langmuir, Freundlich, and Dubinin-Radushkevich models. The linear forms of Langmuir and Freundlich isotherm equations can be expressed as in Eqns. (7) and (8), respectively (41, 42).

$$
\begin{aligned}
& \frac{\mathrm{c}_{\mathrm{e}}}{\mathrm{q}_{\mathrm{e}}}=\frac{1}{\mathrm{q}_{\mathrm{m}} \mathrm{b}}+\frac{\mathrm{C}_{\mathrm{e}}}{\mathrm{q}_{\mathrm{m}}} \\
& \ln q_{e}=\ln K_{F}+\frac{1}{n} \ln C_{e}
\end{aligned}
$$

Where $\mathrm{q}_{\mathrm{e}}$ is the monolayer adsorption capacity of the adsorbent $\left(\mathrm{mgg}^{-1}\right), \mathrm{q}_{\mathrm{m}}$ is the maximum adsorption capacity $\left(\mathrm{mgg}^{-1}\right)$, and b is Langmuir constant $\left(\mathrm{Lmg}^{-1}\right)$ which reflects the affinity between the adsorbate and the adsorbent. $\mathrm{K}_{\mathrm{F}}\left(\left(\mathrm{mgg}^{-1}\right)\left(\mathrm{Lmg}^{-1}\right)^{1 / \mathrm{n}}\right)$ and $\mathrm{n}$ are Freundlich constants which related to the adsorption capacity and intensity of the adsorbents, respectively. Langmuir isotherm supposes a monolayer adsorption on homogenous surfaces without interactions between the adsorbed molecules whereas; Freundlich isotherm presumes a multilayer adsorption of the adsorbate species on heterogeneous surfaces. According to Langmuir isotherm, $\mathrm{q}_{\mathrm{m}}$ and $\mathrm{b}$ values were computed from the linear regression analysis of $\mathrm{C}_{\mathrm{e}} / \mathrm{q}_{\mathrm{e}} \mathrm{vs} \mathrm{C}_{\mathrm{e}}$ plot as represented in Fig. 7(a). Additionally, depending on the Freundlich adsorption isotherm, the Freundlich constants (n and $\mathrm{K}_{\mathrm{F}}$ ) are determined from the intercept and slope of $\ln \mathrm{q}_{\mathrm{e}} \mathrm{vs} \ln \mathrm{C}_{\mathrm{e}}$ plot as represented in (Fig. 7(b)). The Langmuir and Freundlich isotherm constants are listed in Table (2). Furthermore, $\mathrm{q}_{\mathrm{m}}$ can be computed from the Freundlich isotherm model according to Eqn. (9) (43):

$$
\mathrm{K}_{\mathrm{F}}=\mathrm{q}_{\mathrm{m}} / \mathrm{C}_{0}^{(1 / \mathrm{n})}
$$


Obviously, from the data listed in Table (2), the adsorption process can be described well using Langmuir isotherm model compared to the Freundlich isotherm model. This is based on the higher correlation coefficient $\left(\mathrm{R}^{2}\right)$ values and the high compatibility between the calculated $350 \mathrm{q}_{\mathrm{m}}\left(\mathrm{q}_{\mathrm{m}(\mathrm{cal})}\right)$ and the experimental $\mathrm{q}_{\mathrm{m}}\left(\mathrm{q}_{\mathrm{m}(\mathrm{exp})}\right)$ values. The $\mathrm{q}_{\mathrm{max}}$ values obtained from Langmuir 351 model were found to be in the order of SDS-CS/G > EDTA-GL-CS/G > CTAB-CS/G > GL-

$352 \mathrm{CS} / \mathrm{G}>\mathrm{G}$. This trend can be ascribed to the following reasons. (1) The presence of negatively 353 charged surface of the G clay with a huge number of exchangeable ions can result in coating its 354 surface with a water molecule layer; therefore, it showed strong hydrophilicity and high 355 adsorption capacity towards $\mathrm{Mn}(\mathrm{II})$ ions. (2) Addition of large amounts of $-\mathrm{OH}$ and $-\mathrm{NH}_{2}$ 356 functional groups, due to the combination of $\mathrm{G}$ and chitosan polymer, can result in enhancement 357 in the adsorption capacity towards Mn(II) ions. (3) Further addition of functional groups such as 358 carboxylic groups $(-\mathrm{COOH})$ in EDTA-GL-CS/G composite can bring about increasing the 359 negative charge surface which in turn resulting in more electrostatic attraction of $\mathrm{Mn}(\mathrm{II})$ ions 360 (44). (4) Furthermore, functionalization of the composite with organic anions such as anionic 361 surfactants (SDS) can show more enhancements in their adsorption capacity towards Mn(II) ions. 362 Besides, the negatively charged hydrophilic heads (sulfonate groups $\left(-\mathrm{OSO}_{3}-\right)$ ) of the anionic 363 SDS surfactant might increase the negative surface potentially when they pointed towards the 364 bulk of the solution; and consequently resulting in a strong electrostatic attraction of Mn(II) ions. 365 Hence, the removal would be enhanced. However, with the reference to CTAB-CS/G adsorbent, 366 its adsorption capacity was noticeable although it includes hydrophobic head with a positive 367 charge surface. This is probably returning to electrostatic interaction between the functional 368 groups of the chitosan itself and the ordinary adsorption of the ions inside the pores of the $\mathrm{G}$ clay 369 as well (45). 
371

372

373 Where $\mathrm{C}_{0}(\mathrm{mg} / \mathrm{L})$ and $\mathrm{b}(\mathrm{L} / \mathrm{mg})$ are the initial metal ion concentration and the Langmuir

374 equilibrium constant, respectively. The separation factor values afford essential information about 375 the adsorption process nature, which it may be linear $\left(R_{L}=1\right)$, irreversible $\left(R_{L}=0\right)$, favorable $(0<$ 376

377

378

379

380 381

382 383 384 385 386 387 388 389

to dimensionless separation factor constant $\left(\mathrm{R}_{\mathrm{L}}\right)$ as follows:

$$
\mathrm{R}_{\mathrm{L}}=\frac{1}{1+b \mathrm{C}_{0}}
$$
$\left.R_{L}<1\right)$ or unfavorable $\left(R_{L}>1\right)(46)$. $R_{\mathrm{L}}$ values were estimated at different initial concentrations ranged from 10 to $300 \mathrm{mg} \mathrm{L}^{-1}$ and tabulated in Table 3. For all the experimental data, values of $\mathrm{R}_{\mathrm{L}}$ were found to be lying between 0 and 1, indicating favorable adsorption of $\mathrm{Mn}(\mathrm{II})$ ions on all adsorbents at all concentrations. Further, the adsorption of $\mathrm{Mn}(\mathrm{II})$ ions was considered as favorable because the Freundlich exponent (n) values were found to be $>1$ and in the range of 3.27-5.18 (47).

<Fig. 7.>

\section{<Table 3.>}

Furthermore, the equilibrium data was examined using Dubinin-Radushkevich isotherm model (D-R model). The linearity of D-R model (Eqn. (11)) can be defined as (48):

$$
\ln q_{e}=\ln q_{m}-\beta \varepsilon^{2}
$$

Where $\mathrm{q}_{\mathrm{e}}$ and $\mathrm{q}_{\mathrm{m}}(\mathrm{mg} / \mathrm{g})$ are the equilibrium and the maximum adsorption capacity of the adsorbent, respectively. $\varepsilon$ (Polanyi potential) $=\mathrm{RT} \ln \left(1+\left(1 / \mathrm{C}_{\mathrm{e}}\right), \mathrm{R}\left(8.314 \mathrm{~J} \mathrm{~mol}^{-1} \mathrm{~K}^{-1}\right)\right.$ is the universal gas constant and $\mathrm{T}(\mathrm{K})$ is the absolute temperature. $\left.\beta\left(\mathrm{mol}^{2} / \mathrm{kJ}^{2}\right)\right)$ is the Dubinin- 

$406 \quad r^{2}$ values were closer to unity.

Radushkevich constant associated with the adsorption energy. The D-R constants $\mathrm{q}_{\mathrm{m}}$ and $\beta$ values can be detected from the slope and intercept of the plot of $\operatorname{lnq} \mathrm{q}_{\mathrm{e}}$ against $\varepsilon^{2}$ as presented in Fig. 7(c). The adsorption energy (E) can be determined from the following equation (Eqn. (12)).

$$
E=\sqrt{\frac{1}{2 \beta}}
$$

Notably, the E values obtained from the present study were found to be $<8 \mathrm{~kJ} \mathrm{~mol}^{-1}$ as presented in Table 3, indicating the physisorption of $\mathrm{Mn}(\mathrm{II})$ ions on the adsorbents under investigation because the values are in the range of $5-40 \mathrm{~kJ} \mathrm{~mol}^{-1}$ declared for the physisorption (49). However, the results did not follow well the D-R model, based on the obtained lower correlation coefficient $\left(\mathrm{r}^{2}\right)$ values. According to the above discussion, it could be concluded that $\mathrm{Mn}(\mathrm{II})$ ions adsorption on the aforementioned adsorbents was a monolayer coverage since the estimated experimental data complied well with the Langmuir isotherm model compared to other

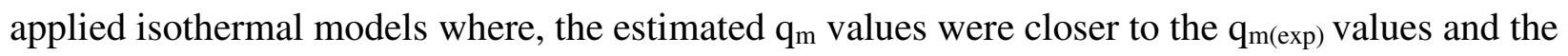

\subsection{Thermodynamic study}

<Table.3>

Thermodynamics parameters associated with the adsorption process such as Gibbs free energy change $\left(\Delta \mathrm{G}^{\mathrm{o}}\right)$, entropy change $\left(\Delta \mathrm{S}^{\mathrm{o}}\right)$, and enthalpy change $\left(\Delta \mathrm{H}^{\mathrm{o}}\right)$ were examined to check the influence of temperature on $\mathrm{Mn}$ (II) ion adsorption under different temperature values (298$318 \mathrm{~K})$ by applying Eqns (13) and (14) $(50,51)$.

$$
\ln \mathrm{K}_{\mathrm{c}}=\Delta \mathrm{S}^{\mathrm{o}} / \mathrm{R}-\Delta \mathrm{H}^{\mathrm{o}} / \mathrm{RT}
$$

$$
\Delta \mathrm{G}^{\mathbf{o}}=\Delta \mathrm{H}^{\mathbf{o}}-\mathrm{T} \Delta \mathrm{S}^{\mathbf{o}}
$$


Where $\mathrm{K}_{\mathrm{c}}$ is a thermodynamic equilibrium constant. $\mathrm{T}$ and $\mathrm{R}$ are absolute temperature $(\mathrm{K})$ and universal gas constant $\left(8.314 \mathrm{~J} \cdot \mathrm{mol}^{-1} \cdot \mathrm{K}^{-1}\right)$, respectively. Regarding to Eqn. $(15), \mathrm{K}_{\mathrm{c}}$ is a constant with a dimensionless unit (51-53).

$$
\Delta \mathrm{G}^{\mathrm{o}}=-\mathrm{RT} \ln \mathrm{K}_{\mathrm{c}}
$$

420 Hence, the dimensionless thermodynamic equilibrium constant $\left(\mathrm{K}_{\mathrm{c}}\right)$ was examined using the 421 distribution coefficient constant $\left(\mathrm{K}_{\mathrm{d}}\right)$ approach (52). In this respect, the distribution coefficient 422 constant $\left(\mathrm{K}_{\mathrm{d}}=\mathrm{q}_{\mathrm{e}} / \mathrm{C}_{\mathrm{e}}\right)$ was first estimated by graphing $\ln \left(\mathrm{q}_{\mathrm{e}} / \mathrm{C}_{\mathrm{e}}\right)$ against $\mathrm{q}_{\mathrm{e}}$ and extrapolating $\mathrm{q}_{\mathrm{e}}$ to 423 zero. Then $\mathrm{K}_{\mathrm{d}}$ was corrected owing to the method proposed by Milonjić to derive the 424 thermodynamic equilibrium constant $\mathrm{K}_{\mathrm{c}}\left(\mathrm{K}_{\mathrm{c}}=\mathrm{K}_{\mathrm{d}} \times 1000\right)$ (53). According Eqns. (13-14), ln $\mathrm{K}_{\mathrm{c}}$ vs. $4251 / \mathrm{T}$ was plotted (Fig. 8) and from the intercept and slope the $\Delta \mathrm{H}^{\mathrm{o}}$ and $\Delta \mathrm{S}^{\mathrm{o}}$ values were calculated, 426 then $\Delta \mathrm{G}^{\mathrm{o}}$ values were estimated. The thermodynamic constants were tabulated in Table (4). The $427 \Delta \mathrm{G}^{\mathrm{o}}$ values were found to be in the ranges of $(-14.5$ to -15.8$),(-15.50$ to -16.60$),(-17.10$ to -18.60$)$, 428 (-17.50 to -18.80$)$, and (-16.0 to $\left.-17.2 \mathrm{kJmol}^{-1}\right)$ for G, GL-CS/G, EDTA-GL-CS/G, SDS-CS/G and 429 CTAB-CS/G adsorbents, respectively. Moreover, the results also indicated the spontaneous nature 430 of $\mathrm{Mn}(\mathrm{II})$ ions sorption on the aforementioned adsorbents because it was found that the values of $431 \Delta \mathrm{G}^{\mathrm{o}}$ increase in the negative direction with increasing the temperature. Additionally, the positive 432 enthalpy $\left(\Delta \mathrm{H}^{\mathrm{o}}\right)$ indicates the endothermic nature of the adsorption process. The positive $\Delta \mathrm{S}^{\mathrm{o}}$ values 433 for all aforementioned adsorbents revealed an increase in the randomness at the solid-solution 434 interface during the adsorption process which in turn indicated an accumulation of Mn(II) ions 435 (54). In general, based on the calculated $\Delta \mathrm{H}^{\circ}$ and $\Delta \mathrm{G}^{\circ}$ values, it can be concluded that the 436 adsorption of $\mathrm{Mn}(\mathrm{II})$ ions on the aforementioned adsorbents is a physisorption as $\Delta \mathrm{H}^{\mathrm{o}}$ values is 437 smaller than $40 \mathrm{~kJ} \mathrm{~mol}^{-1}$, and $\Delta \mathrm{G}^{\circ}$ values lies in the range of -20 to $0 \mathrm{~kJ} \mathrm{~mol}^{-1}$ which is characteristic 438 to the physisorption process (55). 
<Fig. 8>

<Table 4.>

\subsection{Mechanism of $\mathrm{Mn}(\mathrm{II})$ ions adsorption on the $\mathrm{G}$ clay and its nanocomposites}

The current study revealed that the mechanism of $\mathrm{Mn}(\mathrm{II})$ ions adsorption not only depends

on the number of functional sites in the applied adsorbent but also on the changing in the $\mathrm{pH}$ value

449 as illustrated in Scheme (1). The removal of $\mathrm{Mn}(\mathrm{II})$ ions was small at low $\mathrm{pH}$ values $(\mathrm{pH}<5)$ then

450 it increased slowly until it reached maximum at higher $\mathrm{pH}$ values (ca. $\mathrm{pH}$ 6.5). Based on the results,

451 the mechanism of the manganese ion removal depended on the $\mathrm{pH}$ value and the structure of the

452 utilized adsorbents. There are various adsorption/exchange sites present in the $\mathrm{G}$ clay since it 453 contains various hydrous oxides such as $\mathrm{SiO}_{2}, \mathrm{Fe}_{2} \mathrm{O}_{3}, \mathrm{Al}_{2} \mathrm{O}_{3}$, and others (56). Accordingly, the 454 adsorption mechanisms of $\mathrm{Mn}^{2+}$ ions on $\mathrm{G}$ clay and its nanocomposites are summarized in Scheme 455 1. Where, -G represents the intrinsic sites the glauconite clay. The glauconite clay has on its surface 456 hydroxyl functional groups $(-\mathrm{GOH})$ at which adsorption of the contaminants is frequently 457 occurring. The surface hydroxyl groups are amphoteric; therefore, they are turned into positively 458 charged hydroxylated sites $\left(\mathrm{GOH}_{2}{ }^{+}\right)$at $\mathrm{pH}$ values lower than the $\mathrm{pH}_{\mathrm{pzc}}$ values of the prepared 459 compounds (Eqn 1, Scheme 1). The amino groups of the modified chitosan nanocomposites are 460 also protonated in the acidic media, according to Eqns 2 and 3 (Scheme 1), and converted into 461 positively charged functional groups. Similar results are published for other chitosan composites 462 (57). Consequently, in acidic media, the adsorption efficiency will be low due to the electrostatic 
463 repulsion between the $\mathrm{Mn}^{2+}$ ions and the aforementioned positively charged functional groups.

464 The removal of $\mathrm{Mn}^{2+}$ ions can also proceed by the ion exchange mechanism, according to Eqn 4

465 (Scheme 1). As such, every one $\mathrm{Mn}^{2+}$ ion can exchange two $\mathrm{K}^{+}$cations of that clay. Furthermore,

466 the removal of $\mathrm{Mn}^{2+}$ ions by utilizing the chitosan composites is probably due to some adsorption

467 processes through the porous structure of the G clay and some complexation interactions between

468 the manganese ions and oxygen and/or nitrogen atoms of functional groups of those composites

469 as well, as presented in Eqns (5) and (6) in Scheme 1. These results are compatible with some

470 reported mechanisms $(56,58)$. On the contrary, the removal efficiency enhanced by increasing the

$471 \mathrm{pH}$ value above $\mathrm{pH}_{\mathrm{pzc}}$ values of the $\mathrm{G}$ clay $\left(\mathrm{pH}_{\mathrm{pzc}}=6.4\right)$ and its nanocomposites $\left(\mathrm{pH}_{\mathrm{pzc}}=5.61-5.88\right)$.

472 This is attributing to the electrostatic attraction between $\mathrm{Mn}^{2+}$ cations and the negatively charged

473 particles of $\mathrm{G}$ clay and its nanocomposites at those higher $\mathrm{pH}$ values (Eqns 5 and 7; Scheme 1).

474 Where, at those $\mathrm{pH}$ values, the hydroxylated sites of the $\mathrm{G}$ clay, amino groups of the chitosan

475 composites, and carboxylic groups of the EDTA modified composites may undergo deprotonation,

476 as outlined in Eqns (7), (9), and (11). This resulted in an enhancement of the electrostatic attraction

477 and/or complexation between $\mathrm{Mn}^{2+}$ cations and the negatively charged groups such as $-\mathrm{GO}^{-},-\mathrm{NH}^{-}$

478 and $-\mathrm{COO}^{-}$of the $\mathrm{G}$ clay, chitosan, and EDTA components of the nanocomposites, respectively,

479 as presented in Eqns (8), (10), and (12). These adsorption mechanisms are compatible with the

480 reported ones for similar EDTA-modified molecules (59). The CTAB component of the CTAB

481 modified nanocomposite may also played a role in the manganese removal in addition to the

482 aforementioned significant roles. The contribution of CTAB in the removal process is probably

483 through a weak complexation between the manganese cations and the nitrogen atoms of its tertiary

484 amino groups $\left(\left(\mathrm{CH}_{3}\right)_{3} \mathrm{~N}-\right)$ and its bromide ions in the presence of some hydroxide anions, at

485 alkaline $\mathrm{pH}$ values (Eqn 16, Scheme 1). The suggested mechanism for the adsorption by using 
CTAB-modified composite is in accordance with those reported for similar composites modified

487 with some cationic surfactants (60). It is worth noting that the SDS-CS/G composite brought about

488 the highest manganese removal percentage. This is probably attributing to the contribution of the

489 sulfonate headgroups of the SDS surfactant in the adsorption process for this composite, as

490 represented in Eqns 13 and 14 in Scheme 1, along with the aforementioned roles of the G clay and

491 chitosan components of this composite. Where, the sulfonate groups (-OSO $\left.3^{-}\right)$may undergo

492 ionization at higher $\mathrm{pH}$ values (Eqn 13 in Scheme 1). Then, there will be an electrostatic attraction

493 and/or complexation between these negatively charged sulfonate groups and $\mathrm{Mn}^{2+}$ cations, which

494 resulted in the highest removal efficiency compared to the other studied adsorbents. Besides, the

495 removal by using the SDS-CS/G nanocomposite may also proceed through an additional cation

496 exchange mechanism between $\mathrm{Na}^{+}$ions of the SDS component and $\mathrm{Mn}^{2+}$ ions in the solution (Eqn.

497 15; Scheme 1). The suggested mechanism for SDS-modified nanocomposite is consistent with

498 those reported for similar modified anionic surfactant composites (61). Additionally, it is reported 499 that generally the adsorption of metal ions can include surface precipitation, physical and chemical 500 adsorption, and ion exchange (56). Similar behavior has been reported for adsorption of $\mathrm{Cu}$ ions 501 (62).

502

<Scheme 1>

503

504

3.7. Regeneration studies

Regeneration and reuse of any used adsorbent is an important factor to make the sorption 506 process economic. Therefore, we studied the reusability and regeneration of the used raw gluconite 507 clay and its as-prepared nanocomposites. The adsorption of $\mathrm{Mn}$ (II) ions was achieved under 508 optimal adsorption conditions for $4 \mathrm{~h}$ contact time, $\mathrm{pH} 6.5$ at room temperature ca. $25^{\circ} \mathrm{C} \pm 1$. 
509 Subsequently, the loaded adsorbents were recovered in $1 \mathrm{M} \mathrm{HCl}$ as an eluent, then washed with

510 distilled water, and finally drying in oven at $60{ }^{\circ} \mathrm{C}$. The regenerated adsorbents were reused for

$511 \mathrm{Mn}(\mathrm{II})$ ions adsorption and the spent adsorbents were recovered again and subjected to another

512 adsorption cycle. All adsorbents were reused for 4 times after their first regeneration. The results

513 were illustrated in Fig.9. The maximum adsorption capacities $\left(\mathrm{q}_{\mathrm{m}}\right)$ for the sorption/desorption

514 cycles were found to be 3.59, 3.40, 3.1 and $2.65 \mathrm{mgg}^{-1}$ for $\mathrm{G} ; 23.90,23.01,22.54$ and $21.11 \mathrm{mgg}^{-}$

$515{ }^{1}$ for GL-CS/G; 25.78, 25.60, 24.78 and 23.01 $\mathrm{mgg}^{-1}$ for EDTA-GL-CS/G; 26.12, 26.00, 25.76 and

$51624.11 \mathrm{mgg}^{-1}$ for SDS-CS/G; and 25.47, 25.32, 24.31 and $22.66 \mathrm{mg} / \mathrm{g}$ for CTAB-CS/G. The results

517 obtained indicated that the prepared adsorbents had excellent regeneration ability and good

518 performance for the frequent use up to at least four cycles. These results also confirmed that

519 gluconite clay and its modified forms could be regenerated and reused to treat wastewater 520 contaminated with $\mathrm{Mn}(\mathrm{II})$ ions.

<Fig. 9>

522

523

\subsection{Comparison with other adsorbents}

525

Finally, a comparative evaluation of $\mathrm{q}_{\mathrm{m}}$ (maximum adsorption capacity) of the $\mathrm{Mn}(\mathrm{II})$

526 ions adsorption on the aforementioned adsorbents in the current study with those previously

527 reported data. According to Table 5, the as-prepared $\mathrm{G}$ nanocomposites have relatively higher $\mathrm{q}_{\mathrm{m}}$

528 values compared to most of the tabulated adsorbents for $\mathrm{Mn}(\mathrm{II})$ ions removal. Despite, the

529 adsorption capacity of $\mathrm{G}$ was relatively low compared to that of the as-prepared nanocomposites

530 in the current study; it was higher than well-known adsorbents such as activated kaolinites,

531 activated carbon, and zeolite. This indicates that the modified $\mathrm{G}$ clay nanocomposites are 
532 promising and relevant candidates as well as have long-term applicability for the removal of

Mn(II) ions from aqueous media.

\section{$<$ Table 5 >}

\subsection{Application to real wastewater samples}

To highlight the performance of the examined adsorbents to remove Mn(II) ions and how they are applied to the wastewater, water samples were collected from wastewater pools before being treated at the treatment unit at Abu Zaabal for Fertilizers and Chemicals Company (AZFC), Egypt. The chemical composition of the collected water samples as well as the batch adsorption conditions of the experiments were conducted according to the Standard Methods for the Examination of Water and Wastewater (63) as reported previously (25). The chemical composition of wastewater was analyzed and summarized in Table (6). The concentration of $\mathrm{Mn}$ (II) ions in the filtrate was estimated using an atomic absorption spectrophotometer. It is noteworthy that the adsorption experiments were conducted as reported before at $\mathrm{pH}$ 6. Results expressed that the maximum adsorption rate of $\mathrm{Mn}(\mathrm{II})$ ions removal on the $\mathrm{G}, \mathrm{GL}-\mathrm{CS} / \mathrm{G}$, EDTA-GL-CS/G, SDS$\mathrm{CS} / \mathrm{G}$, and CTAB-CS/G adsorbents were determined to be $94.10 \%, 81.85 \%, 83.90 \%, 86.18 \%$ and $82.42 \%$, respectively. Indicating high efficiency and chemical stability of the aforementioned adsorbents for removing the $\mathrm{Mn}(\mathrm{II})$ ions from wastewater even though the presence of foreign ions (cations and anions), which can well interfere and compete through the adsorption process.

\section{Conclusions}

In summary, this study explored the $\mathrm{Mn}(\mathrm{II})$ ions adsorption from polluted aqueous solutions onto raw gluconite clay and its prepared modified chitosan nanocomposites. The used 
chitosan was modified with glutaraldehyde (GL), ethylenediaminetetraacetic acid (EDTA), sodium dodecyl sulfate (SDS) and cetyltrimethyl ammonium bromide (CTAB), for producing nanocomposites: GL-CS/G, EDTA-GL-CS/G, SDS-CS/G, and CTAB-CS/G, respectively. Various experimental conditions influencing the adsorption process such as $\mathrm{pH}$, adsorbent amount, and contact time were examined. The adsorption results showed that SDS-CS/G nanocomposite has the highest adsorption capacity $\left(27.74 \mathrm{mgg}^{-1}\right)$ toward the removal of $\mathrm{Mn}$ (II) ions from polluted aqueous media. Moreover, the Langmuir isotherm and the pseudo-second-order kinetic model fitted well the adsorption process. The positive $\Delta \mathrm{H}^{\circ}$ values and the negative $\Delta \mathrm{G}^{\circ}$ values demonstrated that the process of $\mathrm{Mn}$ (II) ions adsorption was endothermic and spontaneous. Eventually, overall these aspects, including high adsorbents capacity, low cost and the possibility of regeneration make the as-prepared nanocomposites as a promising candidate adsorbents for removing $\mathrm{Mn}(\mathrm{II})$ ions from polluted aqueous solutions.

\section{Acknowledgments}

The authors are thankful to the unidentified reviewers whose comments and recommendations have significantly improved the quality of this manuscript.

1. Yang J, Huang B, Lin M. Adsorption of Hexavalent Chromium from Aqueous Solution by a Chitosan/Bentonite Composite: Isotherm, Kinetics, and Thermodynamics Studies. Journal of Chemical \& Engineering Data. 2020;65(5):2751-63.

2. Sobeih MM, El-Shahat MF, Osman A, Zaid MA, Nassar MY. Glauconite clayfunctionalized chitosan nanocomposites for efficient adsorptive removal of fluoride ions from polluted aqueous solutions. RSC Advances. 2020;10(43):25567-85.

3. Alvarez-Bastida C, Martínez-Miranda V, Solache-Ríos M, Linares-Hernández I, TeutliSequeira A, Vázquez-Mejía G. Drinking water characterization and removal of manganese. Removal of manganese from water. Journal of Environmental Chemical Engineering. 2018;6(2):2119-25. 
4. Mehrali-Afjani M, Nezamzadeh-Ejhieh A. Efficient solid amino acid-clinoptilolite nanoparticles adsorbent for $\mathrm{Mn}$ (II) removal: A comprehensive study on designing the experiments, thermodynamic and kinetic aspects. Solid State Sciences. 2020;101:106124.

5. Nadaska G, Lesny J, Michalik I. Environmental aspect of manganese chemistry. 2012. Hungarian Electronic Journal of Sciences-http://heja szif hu/ENV/ENV-100702-A/env100702a pdf Cited. 2018;17.

6. Yadav VB, Gadi R, Kalra S. Clay based nanocomposites for removal of heavy metals from water: a review. Journal of environmental management. 2019;232:803-17.

7. Basu N, Nam D-H, Kwansaa-Ansah E, Renne EP, Nriagu JO. Multiple metals exposure in a small-scale artisanal gold mining community. Environmental research. 2011;111(3):463-7.

8. $\quad \mathrm{Li} \mathrm{Y}, \mathrm{Xu} \mathrm{Z}, \mathrm{Ma} \mathrm{H}, \mathrm{S}$ Hursthouse A. Removal of Manganese (II) from Acid Mine Wastewater: A Review of the Challenges and Opportunities with Special Emphasis on MnOxidizing Bacteria and Microalgae. Water. 2019;11(12):2493.

9. Carolin CF, Kumar PS, Saravanan A, Joshiba GJ, Naushad M. Efficient techniques for the removal of toxic heavy metals from aquatic environment: A review. Journal of environmental chemical engineering. 2017;5(3):2782-99.

10. Nassar MY, Ahmed IS, Hendy HS. A facile one-pot hydrothermal synthesis of hematite $(\alpha-\mathrm{Fe} 2 \mathrm{O} 3)$ nanostructures and cephalexin antibiotic sorptive removal from polluted aqueous media. Journal of Molecular Liquids. 2018;271:844-56.

11. Nassar MY, Ali EI, Zakaria ES. Tunable auto-combustion preparation of TiO2 nanostructures as efficient adsorbents for the removal of an anionic textile dye. RSC Advances. 2017;7(13):8034-50.

12. Wingenfelder U, Nowack B, Furrer G, Schulin R. Adsorption of $\mathrm{Pb}$ and $\mathrm{Cd}$ by aminemodified zeolite. Water Research. 2005;39(14):3287-97.

13. Djomgoue P, Siewe M, Djoufac E, Kenfack P, Njopwouo D. Surface modification of Cameroonian magnetite rich clay with Eriochrome Black T. Application for adsorption of nickel in aqueous solution. Applied surface science. 2012;258(19):7470-9.

14. Wu Q, Xue Z, Qi Z, Wang F. Synthesis and characterization of PAn/clay nanocomposite with extended chain conformation of polyaniline. Polymer. 2000;41(6):2029-32.

15. Koksal E, Afsin B, Tabak A, Caglar B. Structural characterization of aniline-bentonite composite by FTIR, DTA/TG, and PXRD analyses and BET measurement. Spectroscopy Letters. 2011;44(2):77-82.

16. Yatsyshyn M, Saldan I, Milanese C, Makogon V, Zeffiro A, Bellani V, et al. Properties of glauconite/polyaniline composite prepared in aqueous solution of citric acid. Journal of Polymers and the Environment. 2016;24(3):196-205. 
17. Elsergany M, Shanableh A, Ahsan A. EXPLORATORY STUDY TO ASSESS THE IMPACT OF CHITOSAN/BENTONITE RATIO ON THE METAL REMOVAL CAPACITY OF CHITOSAN MODIFIED BENTONITE CLAY. GLOBAL NEST JOURNAL. 2016;18(2):43743.

18. Pardo L, Domínguez-Maqueda M, Cecilia JA, Pozo Rodríguez M, Osajima J, Moriñigo MÁ, et al. Adsorption of Salmonella in Clay Minerals and Clay-Based Materials. Minerals. 2020;10(2):130.

19. Vanamudan A, Bandwala K, Pamidimukkala P. Adsorption property of Rhodamine 6G onto chitosan-g-(N-vinyl pyrrolidone)/montmorillonite composite. International journal of biological macromolecules. 2014;69:506-13.

20. Zhou Y, Gao B, Zimmerman AR, Fang J, Sun Y, Cao X. Sorption of heavy metals on chitosan-modified biochars and its biological effects. Chemical Engineering Journal. 2013;231:512-8.

21. Ramos V, Rodriguez N, Rodriguez M, Heras A, Agullo E. Modified chitosan carrying phosphonic and alkyl groups. Carbohydrate Polymers. 2003;51(4):425-9.

22. Zhang S, Dong Y, Yang Z, Yang W, Wu J, Dong C. Adsorption of pharmaceuticals on chitosan-based magnetic composite particles with core-brush topology. Chemical Engineering Journal. 2016;304:325-34.

23. Krishna B, Murty D, Prakash BJ. Thermodynamics of chromium (VI) anionic species sorption onto surfactant-modified montmorillonite clay. Journal of Colloid and Interface Science. 2000;229(1):230-6.

24. Zhao M, Wu D, Chang J, Bai Z, Jiang K. Synthesis of cup-like ZnO microcrystals via a CTAB-assisted hydrothermal route. Materials Chemistry and Physics. 2009;117(2-3):422-4.

25. Sobeih MM, El-Shahat M, Osman A, Zaid M, Nassar MY. Glauconite clay-functionalized chitosan nanocomposites for efficient adsorptive removal of fluoride ions from polluted aqueous solutions. RSC Advances. 2020;10(43):25567-85.

26. Association APH, Association AWW, Federation WPC, Federation WE. Standard methods for the examination of water and wastewater: American Public Health Association.; 1915.

27. Ahmaruzzaman M, Gayatri SL. Batch adsorption of 4-nitrophenol by acid activated jute stick char: equilibrium, kinetic and thermodynamic studies. Chemical Engineering Journal. 2010;158(2):173-80.

28. Stafiej A, Pyrzynska K. Adsorption of heavy metal ions with carbon nanotubes. Separation and purification technology. 2007;58(1):49-52.

29. Abdelrahman EA, Tolan DA, Nassar MY. A tunable template-assisted hydrothermal synthesis of hydroxysodalite zeolite nanoparticles using various aliphatic organic acids for the 
removal of zinc (II) ions from aqueous media. Journal of Inorganic and Organometallic Polymers and Materials. 2019;29(1):229-47.

30. Smith EH, Lu W, Vengris T, Binkiene R. Sorption of heavy metals by Lithuanian glauconite. Water Research. 1996;30(12):2883-92.

31. Li Y, Xu Z, Ma H, S. Hursthouse A. Removal of Manganese(II) from Acid Mine Wastewater: A Review of the Challenges and Opportunities with Special Emphasis on MnOxidizing Bacteria and Microalgae. Water. 2019;11(12):2493.

32. Bhatti HN, Nasir AW, Hanif MA. Efficacy of Daucus carota L. waste biomass for the removal of chromium from aqueous solutions. Desalination. 2010;253(1-3):78-87.

33. Nassar MY, Mohamed TY, Ahmed IS, Mohamed NM, Khatab M. Hydrothermally synthesized $\mathrm{Co} 3 \mathrm{O} 4, \alpha-\mathrm{Fe} 2 \mathrm{O} 3$, and $\mathrm{CoFe} 2 \mathrm{O} 4$ nanostructures: efficient nano-adsorbents for the removal of Orange $\mathrm{G}$ textile dye from aqueous media. Journal of Inorganic and Organometallic Polymers and Materials. 2017;27(5):1526-37.

34. Dawodu FA, Akpomie KG. Simultaneous adsorption of Ni (II) and Mn (II) ions from aqueous solution unto a Nigerian kaolinite clay. Journal of materials research and technology. 2014;3(2):129-41.

35. Yavuz Ö, Altunkaynak Y, Güzel F. Removal of copper, nickel, cobalt and manganese from aqueous solution by kaolinite. Water research. 2003;37(4):948-52.

36. Ho Y-S. Second-order kinetic model for the sorption of cadmium onto tree fern: A comparison of linear and non-linear methods. Water Research. 2006;40(1):119-25.

37. Lagergren S. About the theory of so-called adsorption of soluble substances. Kunglia Svenska Vetenskapsakademiens, Handlingar. 1898;24(4):1-39.

38. Yuh-Shan H. Citation review of Lagergren kinetic rate equation on adsorption reactions. Scientometrics. 2004;59(1):171-7.

39. Weber WJ, Morris JC. Proceedings of the International Conference on Water Pollution Symposium. Oxford ; New York: Pergamon Press; 1962.

40. Nassar MY, Moustafa MM, Taha MM. Hydrothermal tuning of the morphology and particle size of hydrozincite nanoparticles using different counterions to produce nanosized $\mathrm{ZnO}$ as an efficient adsorbent for textile dye removal. RSC Advances. 2016;6(48):42180-95.

41. Langmuir I. The adsorption of gases on plane surfaces of glass, mica and platinum. Journal of the American Chemical society. 1918;40(9):1361-403.

42. Freundlich H. Über die Adsorption in Lösungen. Zeitschrift für Physikalische Chemie: De Gruyter; 1907. p. 385-470. 
43. Halsey GD. The Role of Surface Heterogeneity in Adsorption. In: W.G. Frankenburg VIK, Rideal EK, editors. Advances in Catalysis. Volume 4: Academic Press; 1952. p. 259-69.

44. Alkherraz AM, Ali AK, Elsherif KM. Removal of $\mathrm{Pb}$ (II), $\mathrm{Zn}$ (II), $\mathrm{Cu}$ (II) and Cd (II) from aqueous solutions by adsorption onto olive branches activated carbon: Equilibrium and thermodynamic studies. Chemistry International. 2020;6(1):11-20.

45. Anbia M, Amirmahmoodi S. Removal of $\mathrm{Hg}$ (II) and $\mathrm{Mn}$ (II) from aqueous solution using nanoporous carbon impregnated with surfactants. Arabian Journal of Chemistry. 2016;9:S319S25.

46. Ai L, Zhang C, Liao F, Wang Y, Li M, Meng L, et al. Removal of methylene blue from aqueous solution with magnetite loaded multi-wall carbon nanotube: Kinetic, isotherm and mechanism analysis. Journal of Hazardous Materials. 2011;198:282-90.

47. Zhang P, Lo I, O'Connor D, Pehkonen S, Cheng H, Hou D. High efficiency removal of methylene blue using SDS surface-modified $\mathrm{ZnFe} 2 \mathrm{O} 4$ nanoparticles. Journal of Colloid and Interface Science. 2017;508:39-48.

48. Dubinin M. The potential theory of adsorption of gases and vapors for adsorbents with energetically nonuniform surfaces. Chemical Reviews. 1960;60(2):235-41.

49. Onyango MS, Kojima Y, Aoyi O, Bernardo EC, Matsuda H. Adsorption equilibrium modeling and solution chemistry dependence of fluoride removal from water by trivalent-cationexchanged zeolite F-9. Journal of Colloid and Interface Science. 2004;279(2):341-50.

50. Nassar MY, Ahmed IS, Mohamed TY, Khatab M. A controlled, template-free, and hydrothermal synthesis route to sphere-like [small alpha]-Fe2O3 nanostructures for textile dye removal. RSC Advances. 2016;6(24):20001-13.

51. Tran HN, You S-J, Hosseini-Bandegharaei A, Chao H-P. Mistakes and inconsistencies regarding adsorption of contaminants from aqueous solutions: A critical review. Water Research. 2017;120:88-116.

52. Niwas R, Gupta U, Khan AA, Varshney KG. The adsorption of phosphamidon on the surface of styrene supported zirconium (IV) tungstophosphate: a thermodynamic study. Colloids and Surfaces A: Physicochemical and Engineering Aspects. 2000;164(2-3):115-9.

53. Milonjić SK. A consideration of the correct calculation of thermodynamic parameters of adsorption. Journal of the Serbian Chemical Society. 2007;72(12):1363-7.

54. Khobragade M, Pal A. Investigation on the adsorption of Mn (II) on surfactant-modified alumina: Batch and column studies. Journal of Environmental Chemical Engineering. 2014;2(4):2295-305.

55. Govindasamy V, Sahadevan R, Subramanian S, Mahendradas DK. Removal of malachite green from aqueous solutions by perlite. International Journal of Chemical Reactor Engineering. 2009;7(1). 
56. Hao OJ, Tsai CM, Huang CP. The removal of metals and ammonium by natural glauconite. Environment International. 1987;13(2):203-12.

57. Kamal MA, Bibi S, Bokhari SW, Siddique AH, Yasin T. Synthesis and adsorptive characteristics of novel chitosan/graphene oxide nanocomposite for dye uptake. Reactive and Functional Polymers. 2017;110:21-9.

58. Chen N, Zhang Z, Feng C, Li M, Zhu D, Chen R, et al. An excellent fluoride sorption behavior of ceramic adsorbent. Journal of Hazardous Materials. 2010;183(1-3):460-5.

59. Bhatt R, Sreedhar B, Padmaja P. Adsorption of chromium from aqueous solutions using crosslinked chitosan-diethylenetriaminepentaacetic acid. International Journal of Biological Macromolecules. 2015;74:458-66.

60. Bajda T, Kłapyta Z. Adsorption of chromate from aqueous solutions by HDTMA-modified clinoptilolite, glauconite and montmorillonite. Applied Clay Science. 2013;86:169-73.

61. Kuang Y, Zhang X, Zhou S. Adsorption of methylene blue in water onto activated carbon by surfactant modification. Water. 2020;12(2):587.

62. Sayed AS. Removal of toxic pollutants from aqueous solutions by adsorption onto organokaolin. Carbon letters. 2009;10(4):305-13.

63. Wef AA. Standard methods for the examination of waterand wastewater. American Public Health Association, AmericanWater Works Association, Water Environmental Federation, 21st Edition, Washington DC, USA. 2005.

64. Taffarel SR, Rubio J. On the removal of Mn2+ ions by adsorption onto natural and activated Chilean zeolites. Minerals Engineering. 2009;22(4):336-43.

65. Üçer A, Uyanik A, Aygün Ş. Adsorption of Cu (II), Cd (II), Zn (II), Mn (II) and Fe (III) ions by tannic acid immobilised activated carbon. Separation and purification technology. 2006;47(3):113-8.

66. bin Jusoh A, Cheng W, Low W, Nora'aini A, Noor MMM. Study on the removal of iron and manganese in groundwater by granular activated carbon. Desalination. 2005;182(1-3):347-53.

67. Adekola F, Hodonou D, Adegoke H. Thermodynamic and kinetic studies of biosorption of iron and manganese from aqueous medium using rice husk ash. Applied Water Science. 2016;6(4):319-30.

68. Rajic N, Stojakovic D, Jevtic S, Logar NZ, Kovac J, Kaucic V. Removal of aqueous manganese using the natural zeolitic tuff from the Vranjska Banja deposit in Serbia. Journal of Hazardous Materials. 2009;172(2-3):1450-7.

69. Shehap A, Bakr A, Hussein OT. Characterization of Clay/Chitosan Nanocomposites and their Use for Adsorption On Mn (II) from Aqueous Solution. International Journal of Science and Engineering Applications. 2015;4. 
758 70. Reiad NA, Salam OEA, Abadir EF, Harraz FA. Adsorptive removal of iron and manganese 759 ions from aqueous solutions with microporous chitosan/polyethylene glycol blend membrane. 760 Journal of Environmental Sciences. 2012;24(8):1425-32.

761

762 Highlights

$763>$ Adsorptive removal of manganese ions from polluted aqueous media.

$764>$ Natural low-cost Egyptian glauconite clay $(\mathrm{G})$ and its modified-chitosan nanocomposites were 765 applied as adsorbents.

$766>$ Equilibrium, kinetics, and thermodynamics of manganese adsorption process were studied.

$767>$ SDS -CS/G nanocomposite showed the most efficient adsorbents in this study.

768

The raw glauconite and its nanocomposites are promising candidates for manganese ions

769 removal from polluted water.

770

771

772

773

774

775

776

777

778

779

780 Table 1. Kinetic models calculated parameters for Mn(II) adsorption on G, GL-CS/G, EDTA-GL-

781 CS/G, SDS-CS/G and CTAB-CS/G adsorbents. 


\begin{tabular}{|c|c|c|c|c|c|c|c|c|c|c|c|}
\hline \multirow[t]{2}{*}{ Adsorbent } & \multirow{2}{*}{$\begin{array}{c}\mathrm{C}_{0} \\
(\mathrm{mg} / \mathrm{L})\end{array}$} & \multirow[b]{2}{*}{$\begin{array}{l}\text { qe,(exp) } \\
(\mathrm{mg} / \mathrm{g})\end{array}$} & \multicolumn{3}{|c|}{ Pseudo-first-order } & \multicolumn{3}{|c|}{ Pseudo-second-order } & \multicolumn{3}{|c|}{ Intra-particle diffusion } \\
\hline & & & $\mathbf{r}^{2}$ & $\begin{array}{c}\mathrm{k}_{1} \\
(\mathbf{1} / \mathrm{min})\end{array}$ & $\begin{array}{l}\text { qe,(cal) } \\
(\mathrm{mg} / \mathrm{g})\end{array}$ & $\mathbf{r}^{2}$ & $\begin{array}{c}\text { k2 } \\
(\mathrm{g} /(\mathrm{mg} \mathrm{min}))\end{array}$ & $\begin{array}{l}\text { qe,(cal) } \\
(\mathrm{mg} / \mathrm{g})\end{array}$ & $\mathbf{r}^{2}$ & $\begin{array}{c}\mathbf{k}_{\mathbf{i}} \\
\left(\mathrm{mg} /\left(\mathrm{g} \mathrm{min}^{0.5}\right)\right.\end{array}$ & $\begin{array}{c}\mathrm{C} \\
(\mathrm{mg} / \mathrm{g})\end{array}$ \\
\hline $\mathbf{G}$ & 50 & 2.18 & 0.943 & 0.008 & 2.25 & 1.00 & 0.15 & 2.25 & 0.824 & 0.011 & 2.05 \\
\hline GL-CS/G & 50 & 12.67 & 0.842 & 0.006 & 13.30 & 0.999 & 0.006 & 13.35 & 0.743 & 0.29 & 7.79 \\
\hline EDTA-GL-CS & 50 & 16.50 & 0.900 & 0.007 & 17.29 & 0.999 & 0.005 & 17.32 & 0.736 & 0.28 & 12.10 \\
\hline SDS-CS/G & 50 & 17.53 & 0.906 & 0.008 & 17.98 & 0.999 & 0.004 & 18.20 & 0.831 & 0.32 & 12.16 \\
\hline CTAB-CS/G & 50 & 14.18 & 0.825 & 0.006 & 14.82 & 0.999 & 0.005 & 14.80 & 0.720 & 0.29 & 9.43 \\
\hline
\end{tabular}


Table 2. Isothermal parameters for $\mathrm{Mn}(\mathrm{II})$ ions adsorption onto G, GL-CS/G, EDTA-GL-CS/G, SDS-CS/G, and CTAB-CS/G adsorbents.

\begin{tabular}{|c|c|c|c|c|c|c|c|c|c|c|c|c|}
\hline \multirow{2}{*}{ Adsorbent } & \multirow[b]{2}{*}{$\begin{array}{l}\mathrm{q}_{\mathrm{m}(\exp )} \\
\left(\mathrm{mgg}^{-1}\right)\end{array}$} & \multicolumn{3}{|c|}{$\begin{array}{c}\text { Langmuir isotherm } \\
\text { parameters }\end{array}$} & \multicolumn{4}{|c|}{$\begin{array}{c}\text { Freundlich isotherm } \\
\text { parameters }\end{array}$} & \multicolumn{4}{|c|}{$\begin{array}{c}\text { D.-R. isotherm } \\
\text { parameters }\end{array}$} \\
\hline & & $\begin{array}{l}\mathrm{q}_{\mathrm{m}(\mathrm{cal})} \\
\left(\mathrm{mgg}^{-1}\right)\end{array}$ & $\begin{array}{c}\mathrm{b} \\
\left(\mathrm{Lmg}^{-1}\right)\end{array}$ & $r^{2}$ & $\begin{array}{c}\mathrm{q}_{\mathrm{m}(\mathrm{cal})} \\
\left(\mathrm{mgg}^{-1}\right) \\
\left(\text { for } \mathrm{C}_{0}=10-300 \mathrm{mgL}^{-1}\right)\end{array}$ & $\begin{array}{c}\mathrm{K}_{\mathrm{F}} \\
\left(\left(\mathrm{mgg}^{-1}\right)\left(\mathrm{Lmg}^{-1}\right)^{1 / \mathrm{n}}\right)\end{array}$ & $\mathrm{n}$ & $\mathrm{r}^{2}$ & $\begin{array}{c}\mathrm{q}_{\mathrm{m}} \\
\left(\mathrm{mgg}^{-1}\right)\end{array}$ & $\begin{array}{c}\beta \\
\left(\mathrm{mgg}^{-1}\right)^{2}\end{array}$ & $\begin{array}{c}\mathrm{E} \\
\left(\mathrm{kJmol}^{-1}\right)\end{array}$ & $r^{2}$ \\
\hline $\mathrm{G}$ & 3.75 & 3.74 & 0.21 & 0.999 & $1.77-4.81$ & 0.896 & 3.39 & 0.93 & 2.94 & 0.15 & 1.84 & 0.800 \\
\hline GL-CS/G & 24.11 & 24.60 & 0.091 & 0.995 & $9.98-28.17$ & 5.02 & 3.23 & 0.985 & 18.13 & 0.36 & 1.19 & 0.650 \\
\hline EDTA-GL-CS/G & 27.15 & 28.1 & 0.125 & 0.998 & $14.04-30.49$ & 8.31 & 4.37 & 0.984 & 20.77 & 0.03 & 3.79 & 0.640 \\
\hline SDS-CS/G & 27.74 & 28.46 & 0.188 & 0.998 & $16.24-31.14$ & 10.41 & 5.18 & 0.994 & 22.06 & 0.02 & 5.58 & 0.702 \\
\hline CTAB-CS/G & 26.25 & 27.09 & 0.082 & 0.996 & $10.89-30.83$ & 5.42 & 3.27 & 0.987 & 19.61 & 0.28 & 1.32 & 0.650 \\
\hline
\end{tabular}


Table 3. Dimensionless separation factor $\left(\mathrm{R}_{\mathrm{L}}\right)$ determined from Langmuir constant (b) for Mn(II) ion adsorption on G, GL-CS/G, EDTA-GL-CS/G, SDS-CS/G and CTAB-CS/G adsorbents.

\begin{tabular}{|c|c|c|c|c|c|}
\hline \multirow{2}{*}{$\begin{array}{c}\text { Initial } \mathrm{Mn}(\mathrm{II}) \text { ion } \\
\text { concentration }\left(\mathrm{mgL}^{-1}\right)\end{array}$} & \multicolumn{5}{|c|}{ Dimensionless separation factor $\left(\mathrm{R}_{\mathrm{L}}\right)$} \\
\hline & $\mathrm{G}$ & GL-CS/G & EDTA-GL-CS/G & SDS-CS/G & CTAB-CS/G \\
\hline 10 & 0.322 & 0.523 & 0.444 & 0.347 & 0.549 \\
\hline 20 & 0.192 & 0.354 & 0.285 & 0.210 & 0.378 \\
\hline 50 & 0.086 & 0.180 & 0.137 & 0.096 & 0.196 \\
\hline 100 & 0.045 & 0.099 & 0.074 & 0.050 & 0.108 \\
\hline 150 & 0.031 & 0.068 & 0.051 & 0.034 & 0.075 \\
\hline 200 & 0.023 & 0.052 & 0.038 & 0.025 & 0.057 \\
\hline 300 & 0.018 & 0.042 & 0.031 & 0.021 & 0.046 \\
\hline
\end{tabular}


Table 4. Thermodynamic parameters for the adsorption of Mn(II) ions on G, GL-CS/G, EDTA-GL-CS/G, SDS-CS/G, and CTAB-

CS/G adsorbents.

\begin{tabular}{|c|c|c|c|c|c|c|c|c|c|c|c|c|c|}
\hline \multirow{2}{*}{ Adsorbent } & \multirow[b]{2}{*}{$\mathrm{T}(\mathrm{K})$} & \multicolumn{5}{|c|}{$\mathrm{K}_{\mathrm{c}}$ at different $\mathrm{K}$ temperatures } & \multicolumn{5}{|c|}{$\begin{array}{c}\Delta \mathrm{G}^{\mathrm{o}}\left(\mathrm{kJmol}^{-1}\right) \text { at different } \mathrm{K} \\
\text { temperatures }\end{array}$} & \multirow{2}{*}{$\begin{array}{c}\Delta \mathrm{H}^{\mathrm{o}} \\
(\mathrm{kJ} / \mathrm{mol})\end{array}$} & \multirow{2}{*}{$\begin{array}{c}\Delta \mathrm{S}^{\mathrm{o}} \\
(\mathrm{kJ} /(\mathrm{mol} \mathrm{k})\end{array}$} \\
\hline & & 298 & 303 & 308 & 313 & 318 & 298 & 303 & 308 & 313 & 318 & & \\
\hline $\mathrm{G}$ & & 340.6 & 352.6 & 353.2 & 381 & 391 & -14.5 & -14.8 & -15.03 & -15.47 & -15.8 & 5.55 & 0.07 \\
\hline GL-CS/G & & 513.8 & 514 & 519.6 & 524.2 & 527 & -15.5 & -15.7 & -16.0 & -16.3 & -16.6 & 1.40 & 0.06 \\
\hline EDTA-GL-CS/G & & 970.6 & 982 & 1001 & 1062 & 1112 & -17.1 & -17.4 & -17.7 & -18.1 & -18.6 & 5.50 & 0.075 \\
\hline SDS-CS/G & & 1173.3 & 1185 & 1196 & 1222 & 1236 & -17.5 & -17.8 & -18.1 & -18.5 & -18.8 & 2.13 & 0.07 \\
\hline CTAB-CS/G & & 654.7 & 655.3 & 659.5 & 667.1 & 670.4 & -16.0 & -16.3 & -16.6 & -17.0 & -17.2 & 1.03 & 0.057 \\
\hline
\end{tabular}


Table 5. The comparison of maximum adsorption capacities of various materials toward the adsorption of $\mathrm{Mn}(\mathrm{II})$ ions.

\begin{tabular}{|c|c|c|}
\hline Adsorbent & $\underset{(\mathrm{mg} / \mathrm{g})}{\mathbf{q}_{\max }}$ & Reference \\
\hline kaolinite clay & 0.45 & $(35)$ \\
\hline Activated zeolite with $\mathrm{NaCl}$ & 0.78 & $(64)$ \\
\hline Activated carbon immobilized by tannic acid & 1.73 & $(65)$ \\
\hline Granular Activated carbon & 2.54 & $(66)$ \\
\hline Rice husk & 3.21 & $(67)$ \\
\hline Glauconite (G) & 3.75 & Present study \\
\hline Zeolite & 6.96 & (68) \\
\hline Montmorillonite chitosan biocomposite (MMT) & 10.11 & (69) \\
\hline Chitosan/polyethylene glycol blend membrane & 21.70 & $(70)$ \\
\hline Modified Chitosan-glauconite composite (GL-CS/G) & 24.11 & Present study \\
\hline CTAB-modified glauconite (CTAB-CS/G) & 26.25 & Present study \\
\hline EDTA-modified glauconite (EDTA-GL-CS/G) & 27.15 & Present study \\
\hline SDS-modified glauconite (SDS-CS/G) & 27.74 & Present study \\
\hline CTAB-treated mesoporous carbon adsorbent & 43.0 & $(45)$ \\
\hline SDS- treated mesoporous carbon adsorbent & 47.0 & $(45)$ \\
\hline
\end{tabular}


Table 6. Physico-chemical parameters of real wastewater sample after its treatment using the as-prepared adsorbents.

\begin{tabular}{|c|c|c|}
\hline \multirow[b]{2}{*}{ Water quality parameters } & \multicolumn{2}{|c|}{ Content (mg/L) } \\
\hline & $\begin{array}{c}\text { Before } \\
\text { treatment }\end{array}$ & $\begin{array}{c}\text { After treatment } \\
\text { (The obtained range for applying G clay and } \\
\text { its composites) }\end{array}$ \\
\hline $\mathrm{pH}$ & 3.12 & $6-6.5$ \\
\hline Electrical Conductivity $(\mu \mathrm{m} / \mathrm{cm})$ & 9060 & $71.25-85.77$ \\
\hline Turbidity (NTU) & 51.00 & $90.00-98.00 \%$ \\
\hline Total Hardness (mg/L) & 3100 & $90.00-93.84 .00 \%$ \\
\hline COD & 180 & $80.00-84.00 \%$ \\
\hline $\mathrm{P}(\mathrm{mg} / \mathrm{L})$ & 1800 & $88.00-90.10 \%$ \\
\hline T.S (mg/L) & 16500 & $61.15-70.20 \%$ \\
\hline T.D.S (mg/L) & 13300 & $51.00-55.80 \%$ \\
\hline T.S.S (mg/L) & 3200 & $72.11-66.22 \%$ \\
\hline $\mathrm{CL}(\mathrm{mg} / \mathrm{L})$ & 369.2 & $66.41-72.33 \%$ \\
\hline $\mathrm{Fe}(\mathrm{mg} / \mathrm{L})$ & 518 & $96.12-97.87 \%$ \\
\hline $\mathrm{Na}(\mathrm{mg} / \mathrm{L})$ & 610 & $83.20-86.10 \%$ \\
\hline $\mathrm{K}(\mathrm{mg} / \mathrm{L})$ & 150 & $68.80-74.80 \%$ \\
\hline $\mathrm{S}(\mathrm{mg} / \mathrm{L})$ & 3500 & $88.84-92.11 \%$ \\
\hline $\operatorname{Mg}(\mathrm{mg} / \mathrm{L})$ & 190.10 & $87.10-90 \%$ \\
\hline $\mathrm{Mn}(\mathrm{mg} / \mathrm{L})$ & 18.06 & $94.10-82.42 \%$ \\
\hline
\end{tabular}




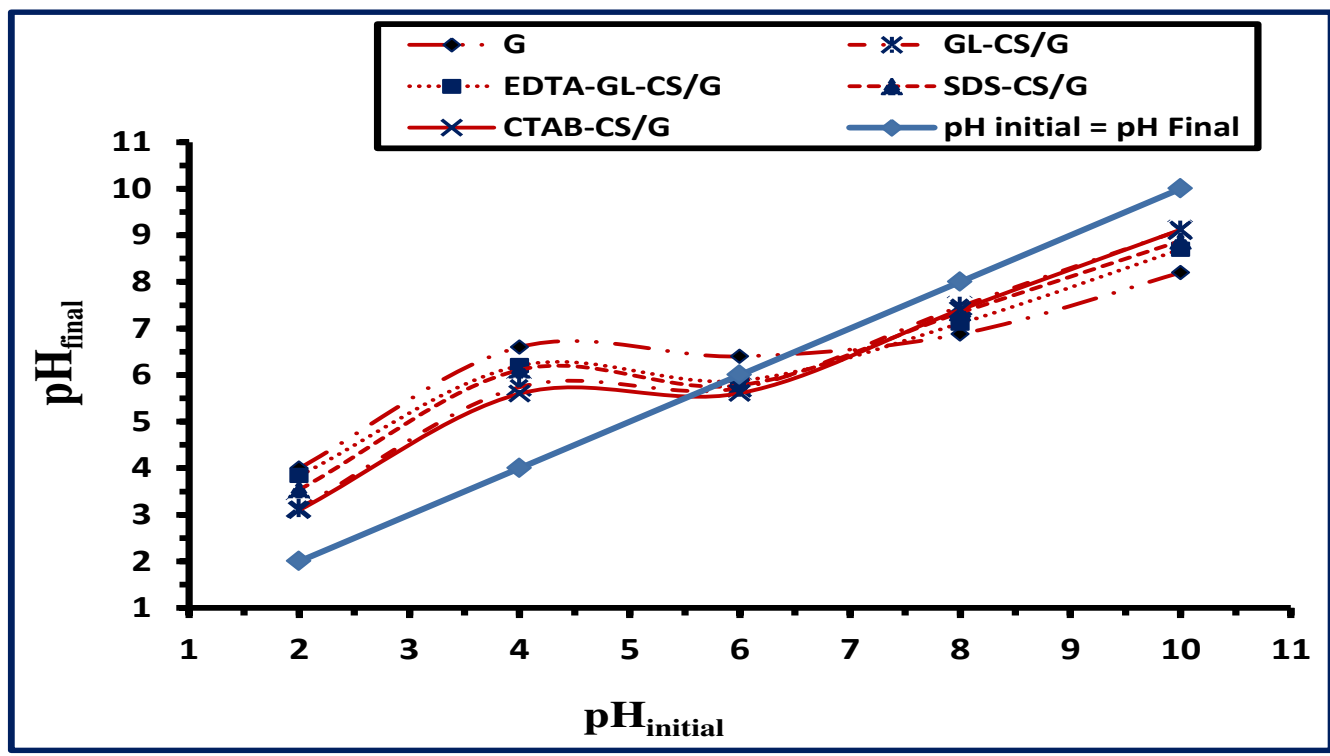

Fig.1. Determination of the point zero charge values of G, GL-CS/G, EDTA-GL-CS/G, SDS-CS/G, and CTAB-CS/G adsorbents.

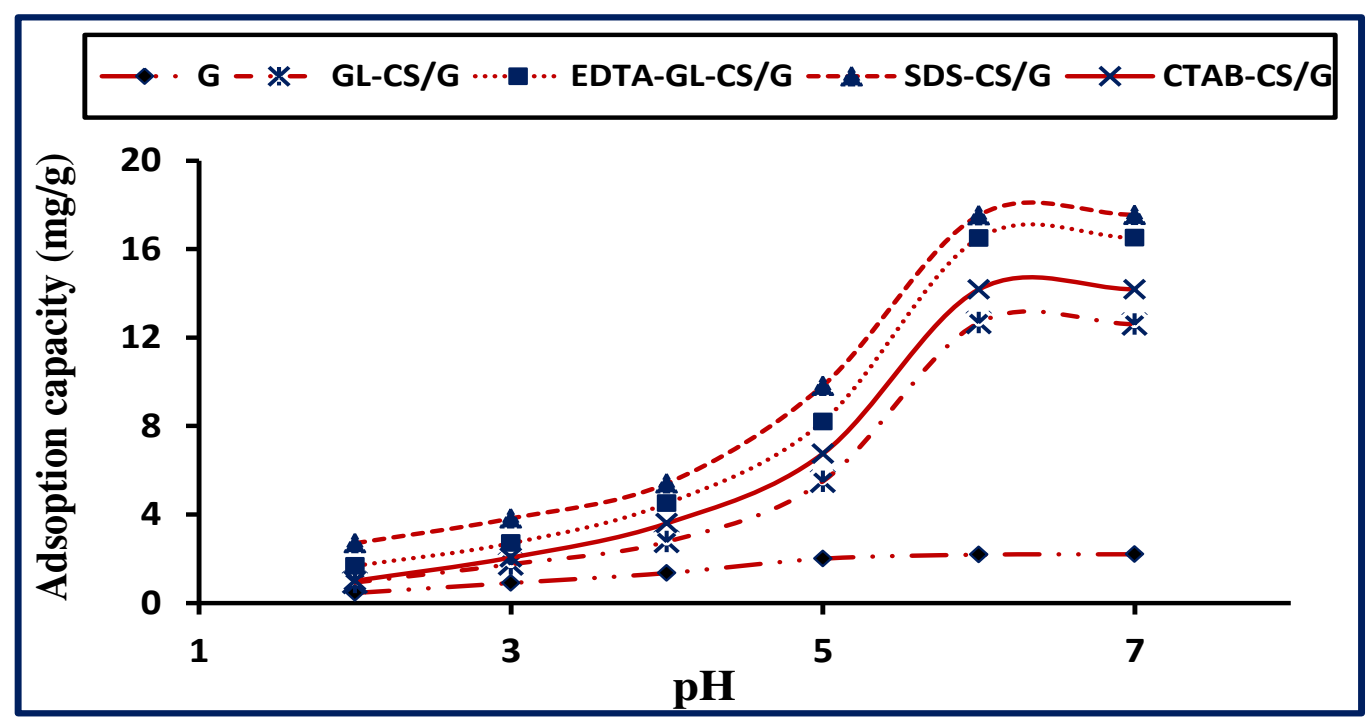

Fig.2. Effect of $\mathrm{pH}$ values on $\mathrm{Mn}$ (II) adsorption onto G, GL-CS/G, EDTA-GL-CS/G, SDS-CS/G, and CTAB-CS/G adsorbents. 


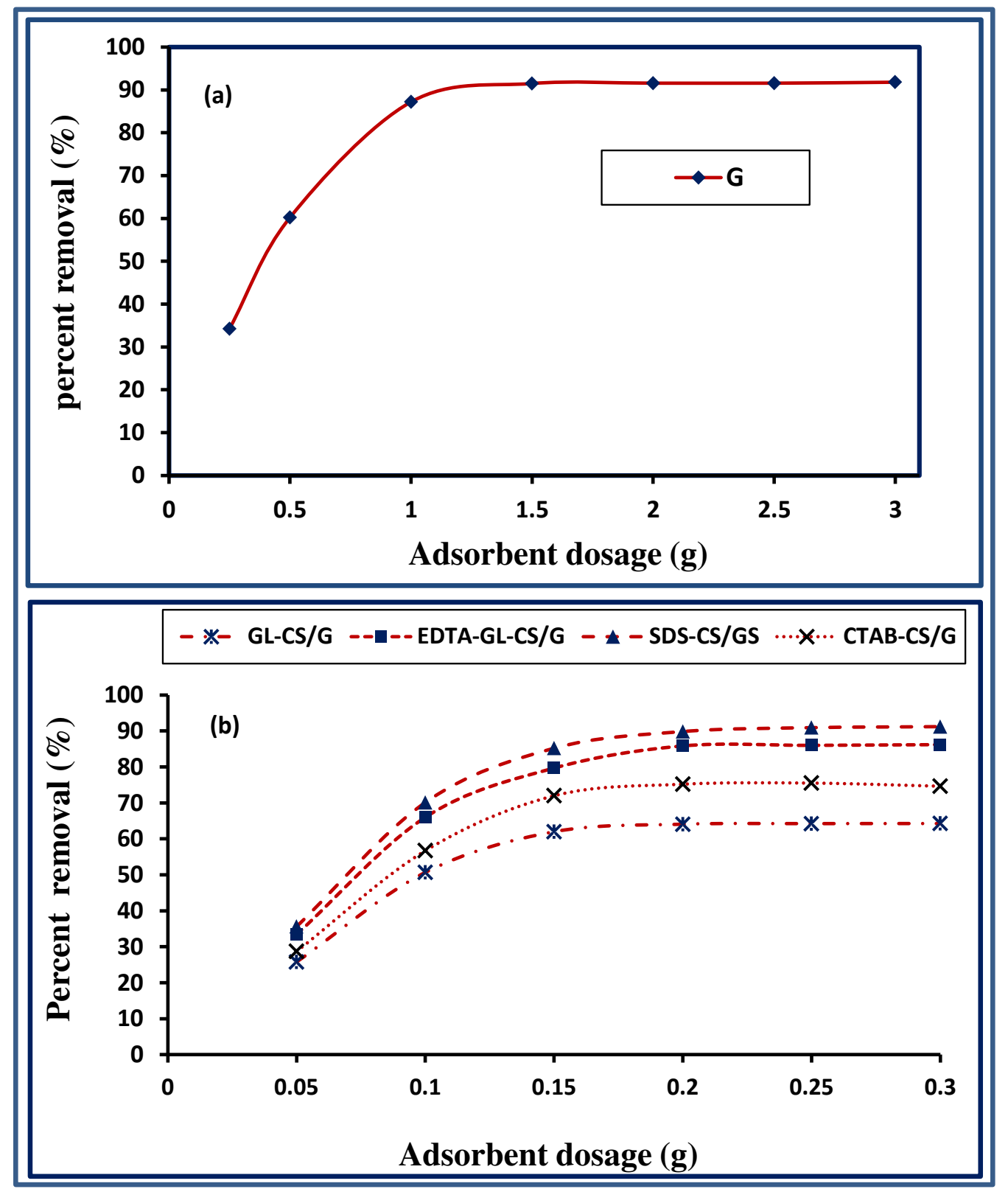

Fig. 3. Influence of adsorbent dosage on $\mathrm{Mn}(\mathrm{II})$ ions removal using $\mathrm{G}$ (a); GL-CS/G, EDTA-GL-CS/G, SDS-CS/G, and CTAB-CS/G (b) adsorbents. 


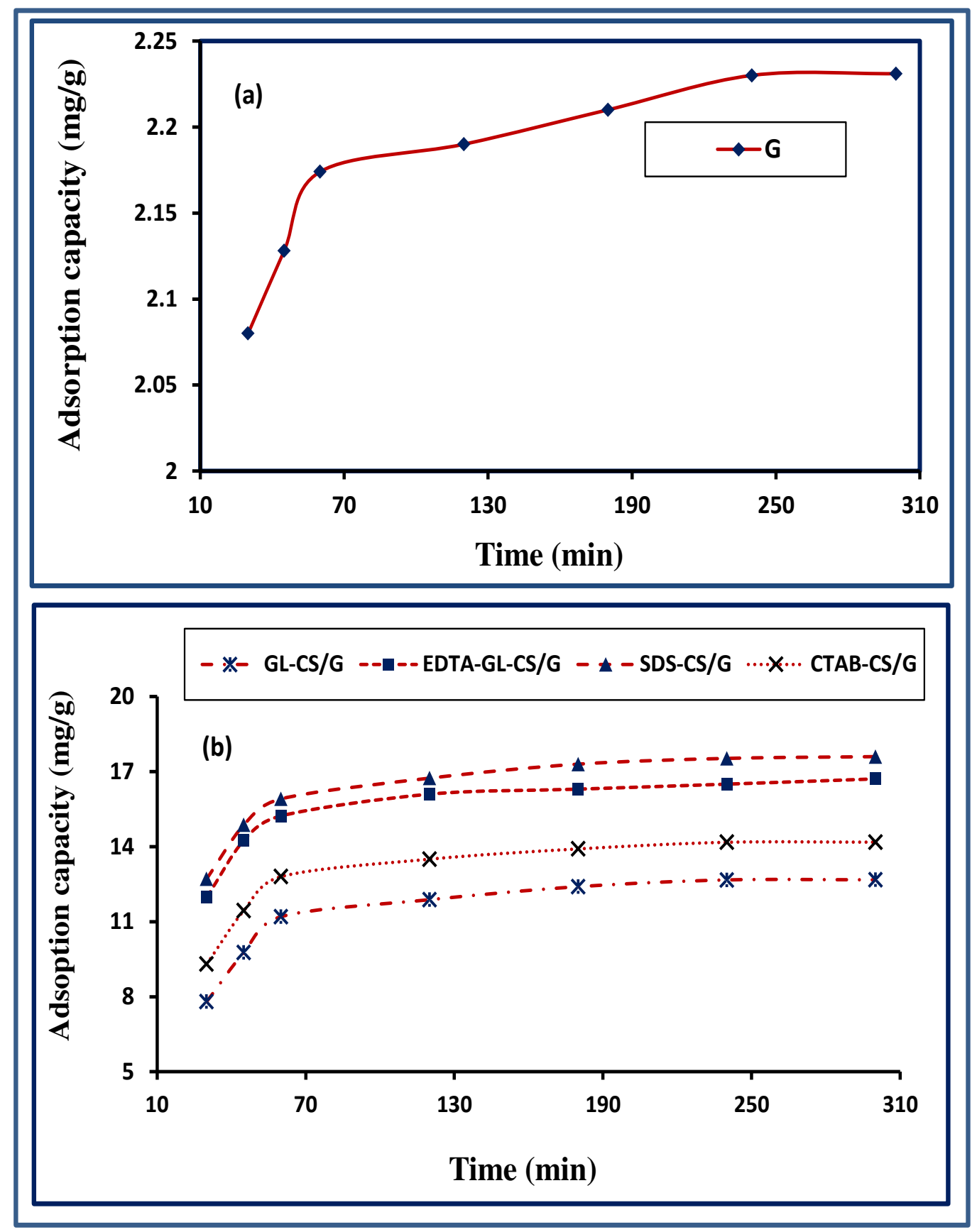

Fig. 4. Influence of contact time on $\mathrm{Mn}$ (II) ions adsorption capacity using G (a); GLCS/G, EDTA-GL-CS/G, SDS-CS/G, and CTAB-CS/G (b) adsorbents. 

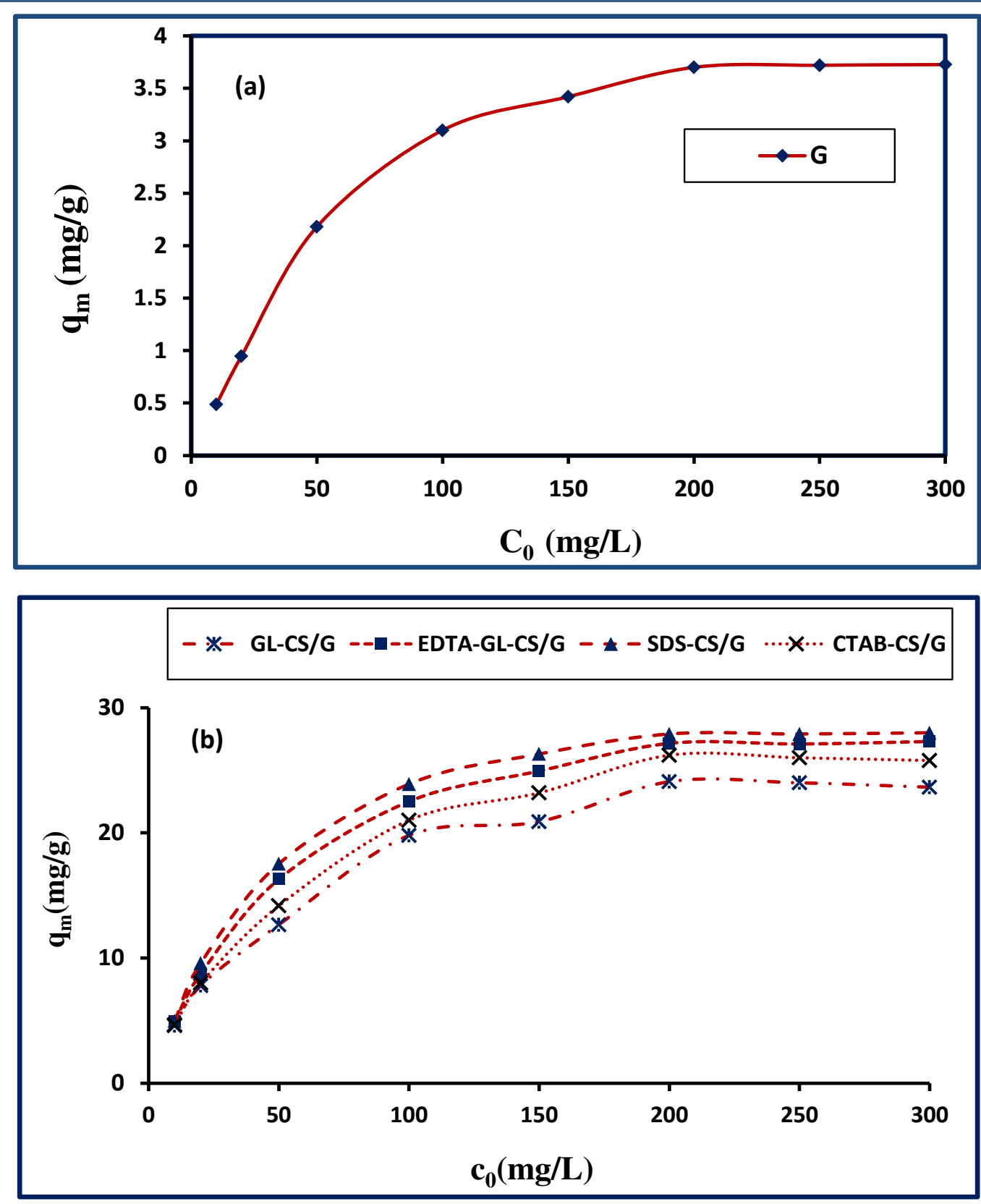

Fig. 5. Influence of initial $\mathrm{Mn}$ (II) ions concentration on adsorption capacity of $\mathrm{G}$ (a); GL-CS/G, EDTA-GL-CS/G, SDS-CS/G, and CTAB-CS/G (b) adsorbents. 


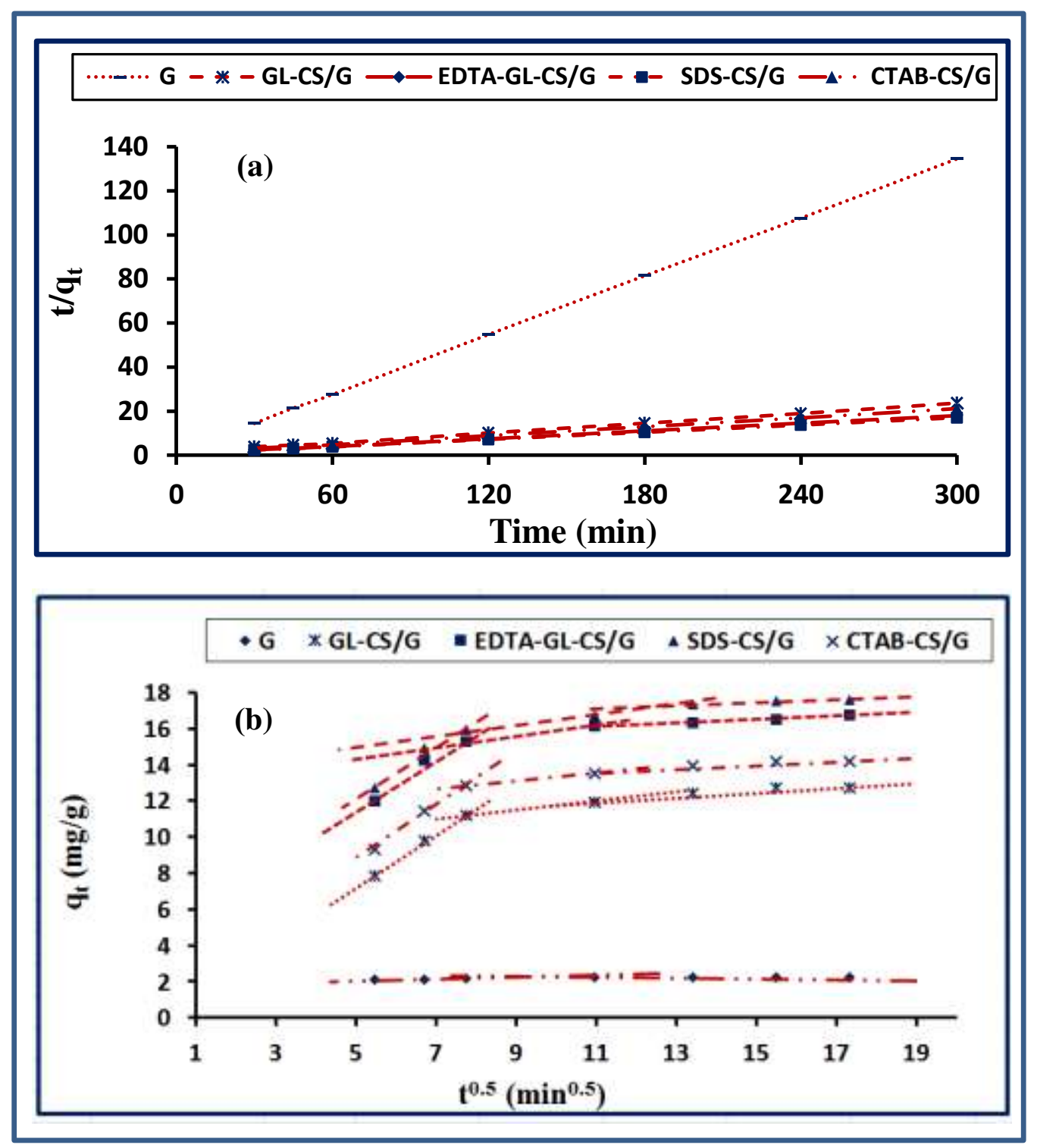

Fig. 6. Pseudo-second-order kinetic model (a), and validation of intra-particle-diffusion model (b) for Mn(II) ions adsorption onto G, GL-CS/G, EDTA-GL-CS/G, SDS-CS/G, and CTAB-CS/G adsorbents. 


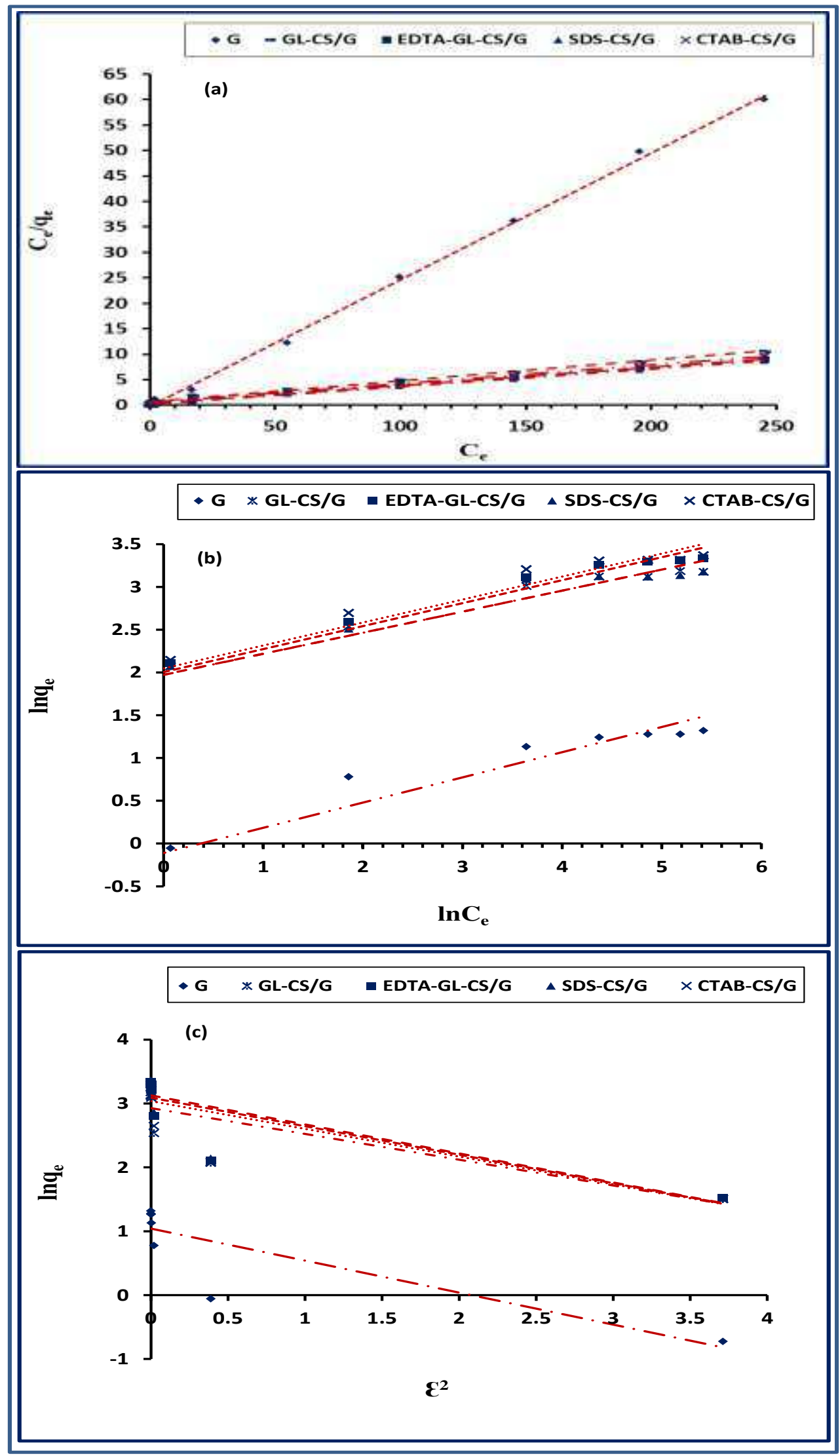

Fig. 7. Adsorption isotherms of Mn(II) ions onto G, GL-CS/G, EDTA-GL-CS/G, SDSCS/G, and CTAB-CS/G adsorbents: Langmuir (a), Freundlich (b), and DubininRadushkevich (c). 


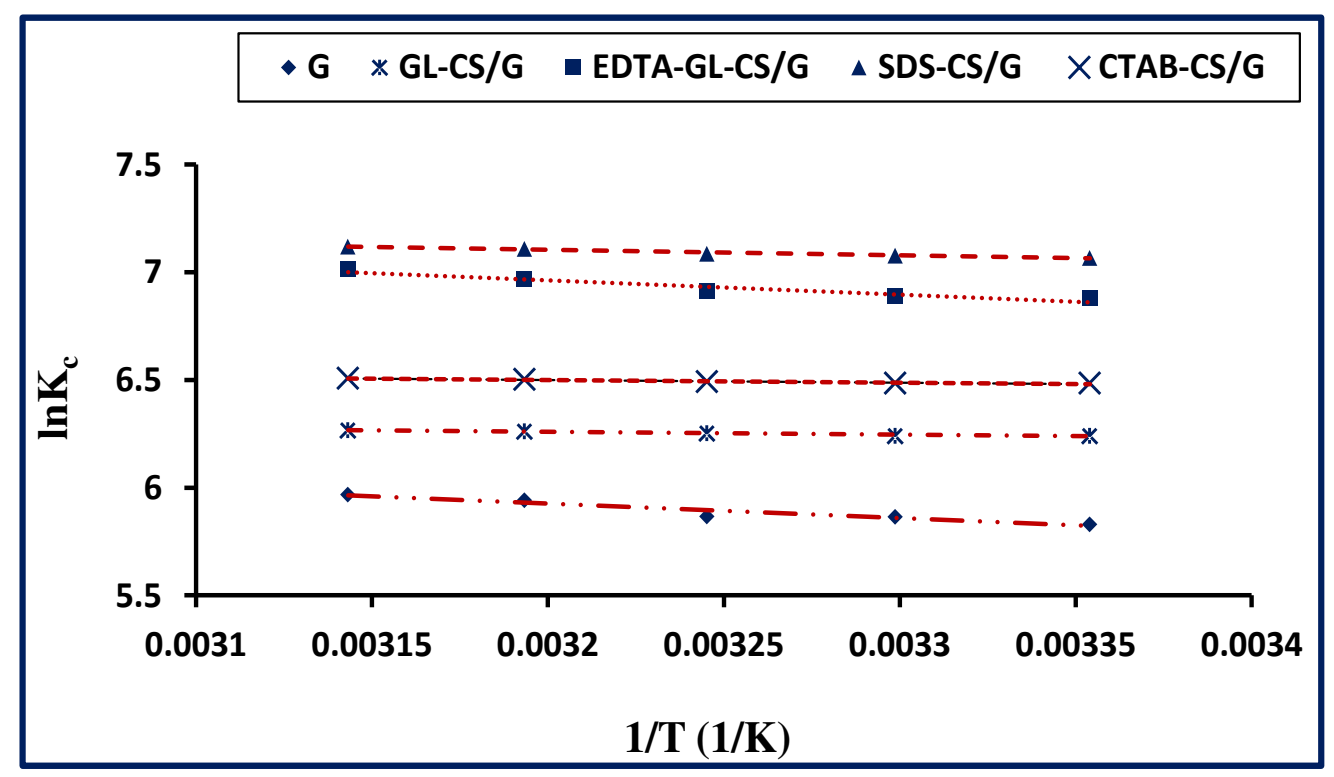

Fig. 8. The plots of $\ln K_{C}$ versus $1 / T$ for $M n(I I)$ ions removal using G, GL-CS/G, EDTA-GL-CS/G, SDS-CS/G, and CTAB-CS/G adsorbents

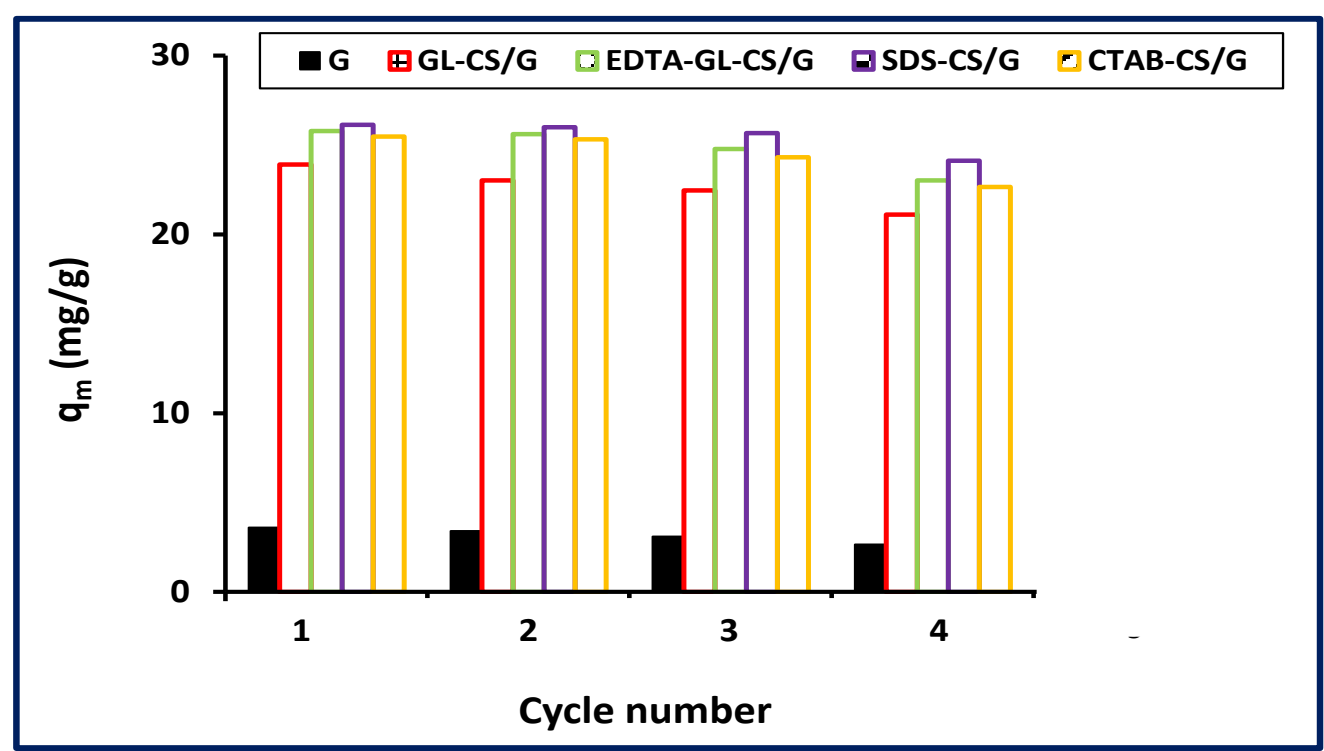

Fig. 9. Regeneration efficiency of G, GL-CS/G, EDTA-GL-CS/G, SDS-CS/G, and CTAB-CS/G adsorbents for $\mathrm{Mn}(\mathrm{II})$ ion adsorption from aqueous media. 


\begin{tabular}{|c|c|c|}
\hline $\mathrm{n}\left(\mathrm{R}^{1} \mathrm{NH}_{2}\right)+\mathrm{Mn}^{2+}$ & $\longrightarrow\left[\mathrm{Mn}\left(\mathrm{NH}_{2} \mathrm{R}^{1}\right)_{\mathrm{n}}\right]^{2+}$ & (5) \\
\hline $\mathrm{x}(-\mathrm{GOH})+\mathrm{Mn}^{2+}$ & $\longrightarrow\left[\mathrm{Mn}(\mathrm{OHG}-)_{\mathrm{x}}\right]^{2+}$ & (6) \\
\hline$-\mathrm{GOH}+\mathrm{OH}^{-}$ & $\longrightarrow-\mathrm{GO}^{*}+\mathrm{H}_{2} \mathrm{O}$ & (7) \\
\hline $2(-\mathrm{GO})+\mathrm{Mn}^{2+}$ & $\longrightarrow$-GO..Mn_.OG- & $(8)$ \\
\hline $\mathrm{R}^{\mathrm{l}} \mathrm{NH}_{2}+\mathrm{OH}$ & $\longrightarrow \mathrm{R}^{1} \mathrm{NH}+\mathrm{H}_{2} \mathrm{O}$ & (9) \\
\hline $\mathrm{R}^{1} \mathrm{NH}+\mathrm{Mn}^{2+}$ & $\longrightarrow \mathrm{R}^{1} \mathrm{NH} . \mathrm{Mn} . \mathrm{NHR}^{1}$ & (10) \\
\hline $\mathrm{R}^{3} \mathrm{COOH}+\mathrm{OH}$ & $\longrightarrow \mathrm{R}^{3} \mathrm{COO}^{-}+\mathrm{H}_{2} \mathrm{O}$ & (11) \\
\hline $2\left(\mathrm{R}^{3} \mathrm{COO}\right)+\mathrm{Mn}^{2-}$ & $\longrightarrow \mathrm{R}^{3} \mathrm{COO} . . \mathrm{Mn} . \mathrm{OOCR}^{3}{ }_{3}$ & (12) \\
\hline $\mathrm{R}^{4} \mathrm{OSO}_{3} \mathrm{Na}+\mathrm{OH}$ & $\longrightarrow \mathrm{R}^{4} \mathrm{OSO}_{3}^{+}+\mathrm{NaOH}$ & (13) \\
\hline $2\left(\mathrm{R}^{4} \mathrm{OSO}_{3}\right)+\mathrm{Mn}^{2+}$ & $\longrightarrow \mathrm{R}^{4} \mathrm{OSO}_{3} . \mathrm{Mn} . . \mathrm{O}_{3} \mathrm{SOR}^{4}$ & (14) \\
\hline $2\left(\mathrm{R}^{4} \mathrm{OSO}_{3} \mathrm{Na}\right)+\mathrm{Mn}^{2-}$ & $\longrightarrow \mathrm{R}^{4} \mathrm{OSO}_{3} . \mathrm{Mn} . \mathrm{O}_{3} \mathrm{SOR}^{4}+2 \mathrm{Na}^{-}$ & (15) \\
\hline $2 \mathrm{R}^{5} \mathrm{~N}\left(\mathrm{CH}_{3}\right)_{3} \mathrm{Br}+\mathrm{Mn}^{2+}+\mathrm{ZOH}$ & $\longrightarrow\left(\left(\mathrm{R}^{5} \mathrm{~N}\left(\mathrm{CH}_{3}\right)_{3}\right)_{2}\right)^{2+}\left[\mathrm{Mn}(\mathrm{OH})_{2} \mathrm{Br}_{2}\right]^{(2.22)-}$ & (16) \\
\hline
\end{tabular}

Scheme 1. Suggested adsorption mechanism of $\mathrm{Mn}(\mathrm{II})$ ions onto G, GL-CS/G, EDTAGL-CS/G, SDS-CS/G, and CTAB-CS/G adsorbents. Where $\mathrm{R}^{1}, \mathrm{R}^{2}, \mathrm{R}^{3}, \mathrm{R}^{4}$, and $\mathrm{R}^{5}$ represent the aliphatic groups in the modified chitosan nanocomposites. 


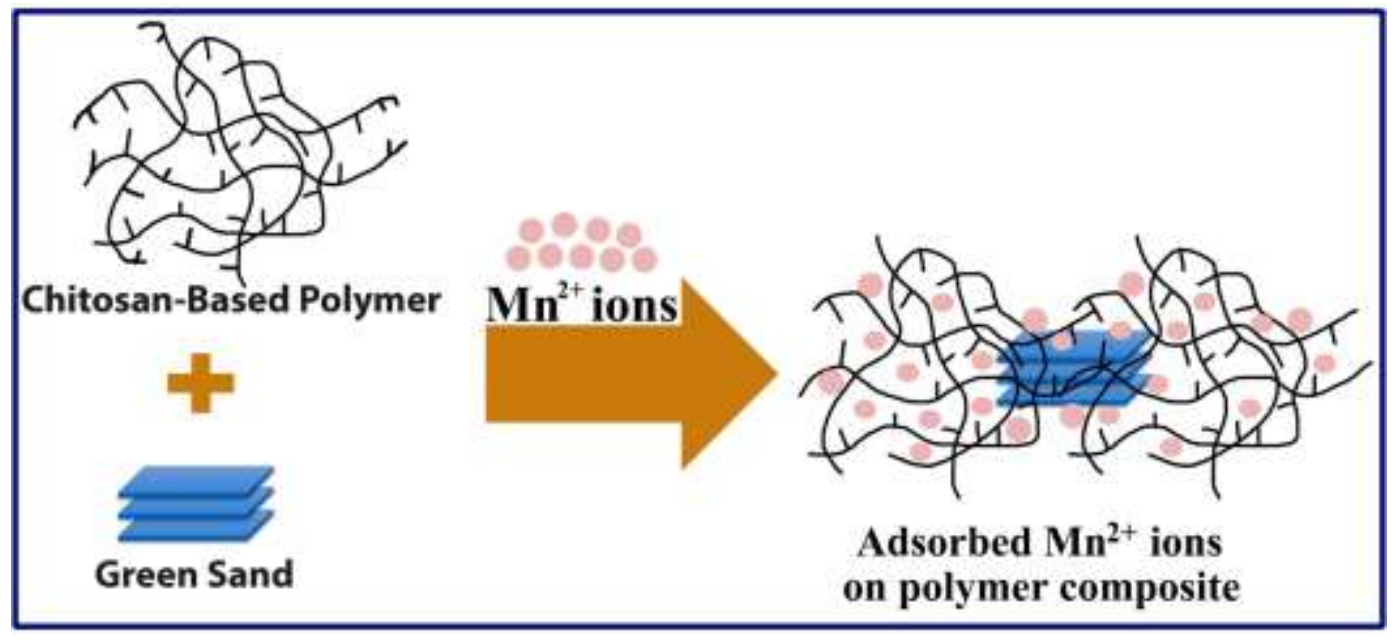

Graphical Abstract 
Figures

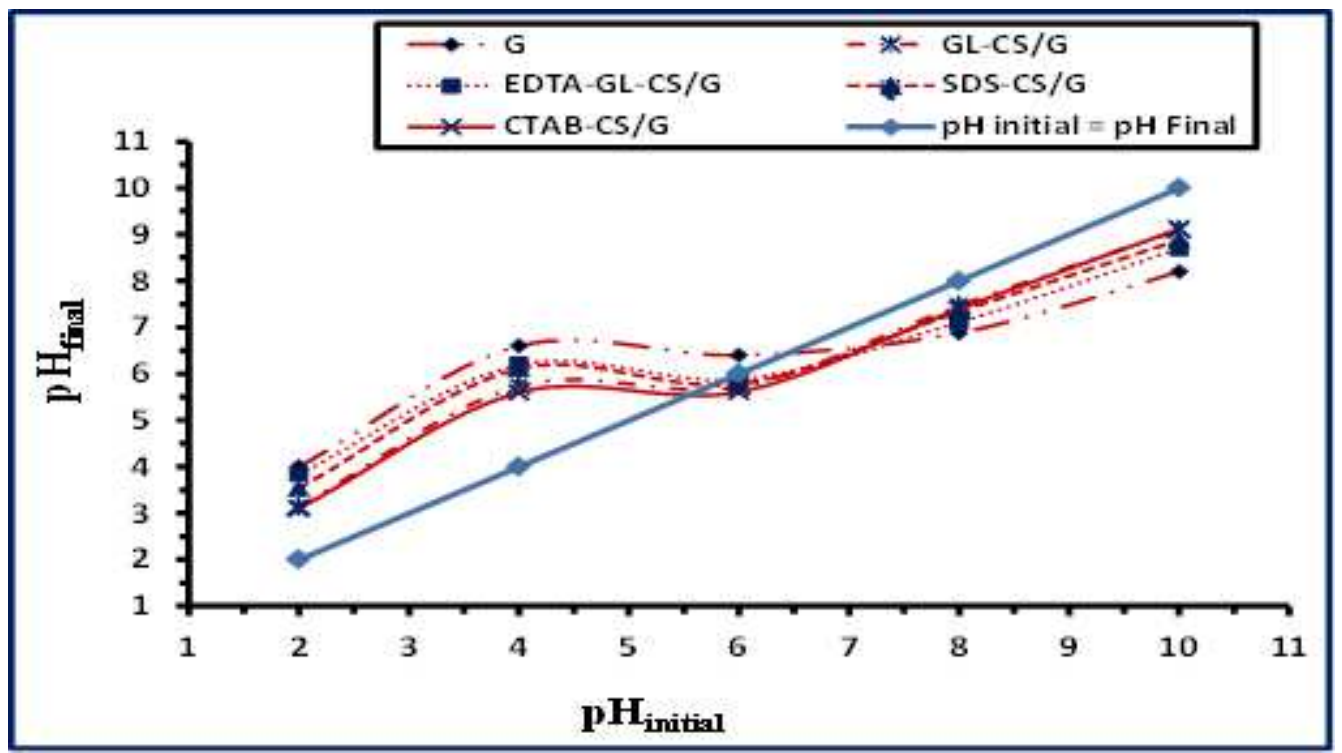

\section{Figure 1}

Determination of the point zero charge values of G, GL-CS/G, EDTA-GL-CS/G, SDS-CS/G, and CTAB-CS/G adsorbents.

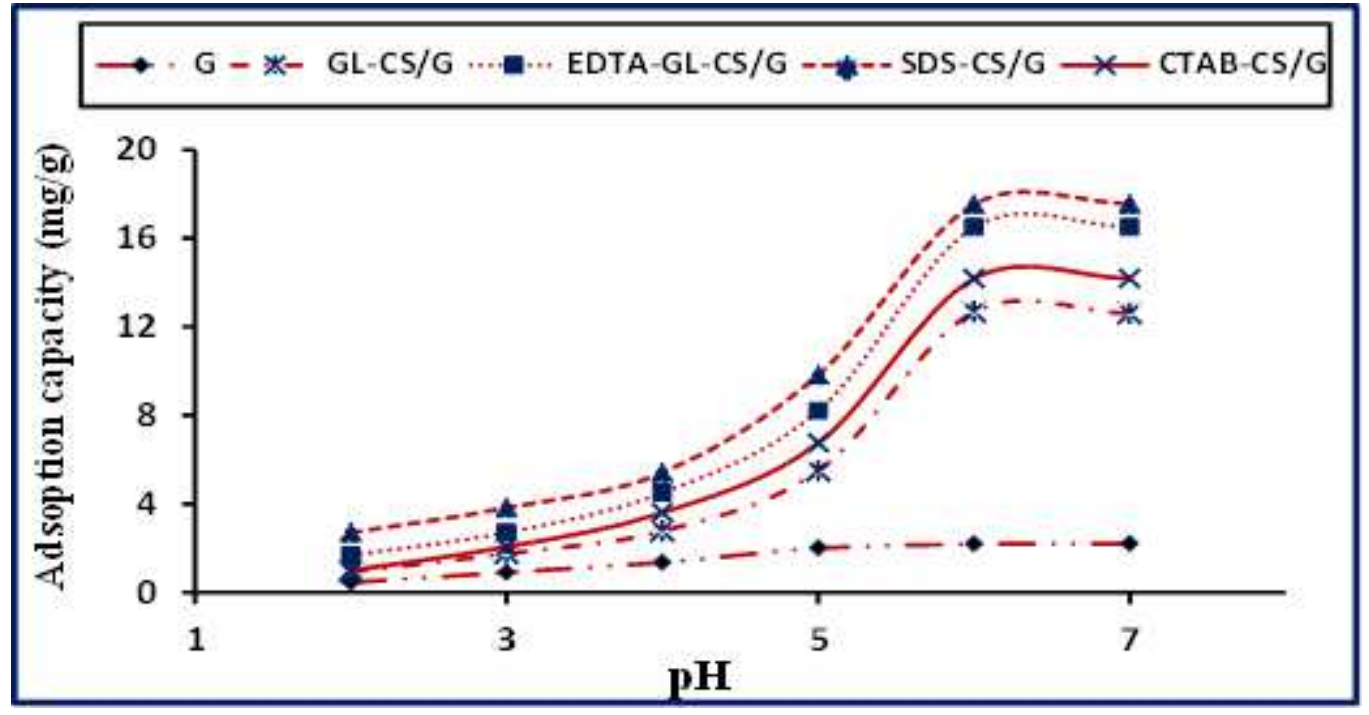

Figure 2

Effect of $\mathrm{pH}$ values on Mn(II) adsorption onto G, GL-CS/G, EDTA-GL-CS/G, SDS-CS/G, and CTAB-CS/G adsorbents. 


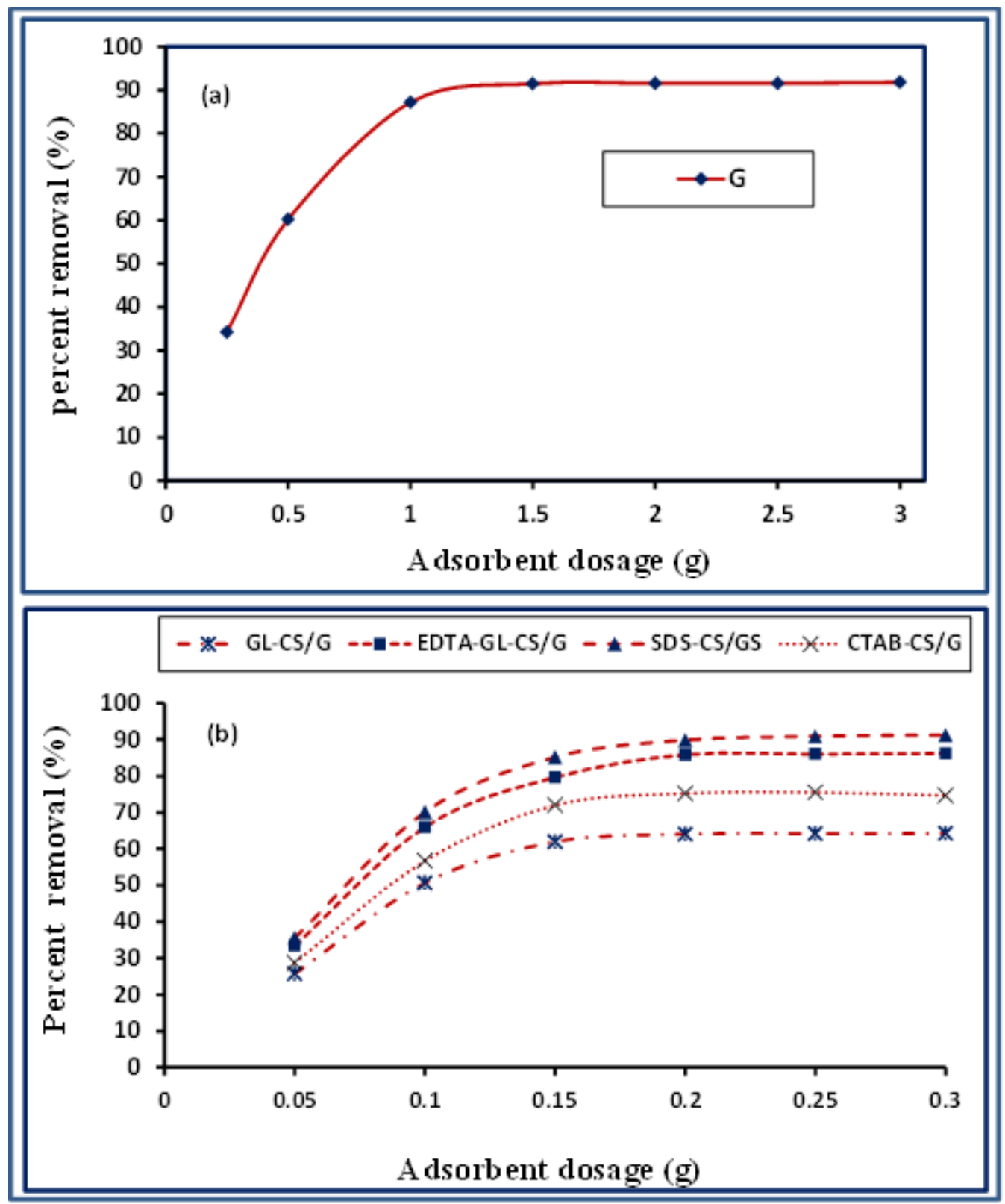

Figure 3

Influence of adsorbent dosage on Mn(II) ions removal using G (a); GL-CS/G, EDTA-GL-CS/G, SDS-CS/G, and CTAB-CS/G (b) adsorbents. 

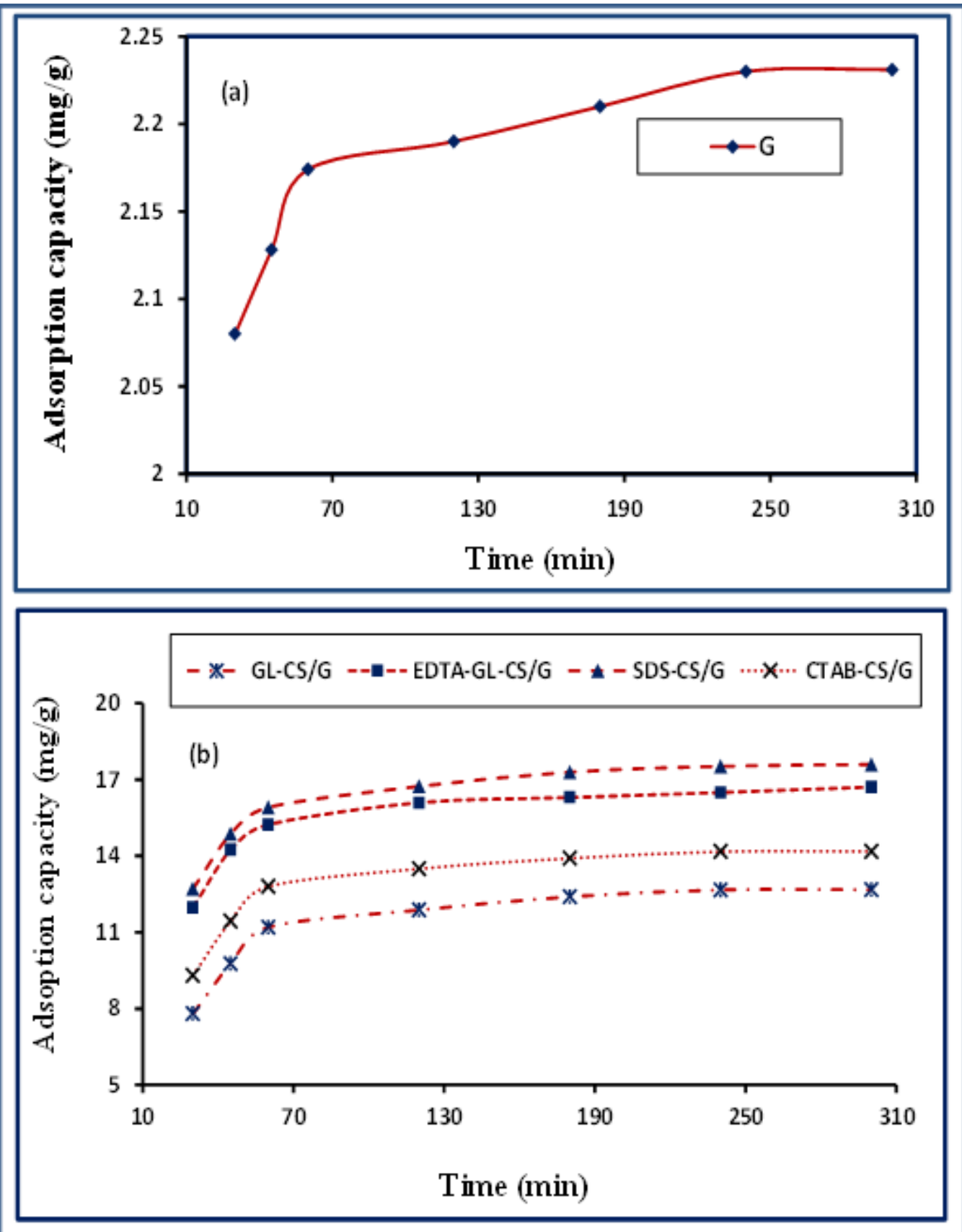

Figure 4

Influence of contact time on Mn(II) ions adsorption capacity using G (a); GL-CS/G, EDTA-GL-CS/G, SDS$\mathrm{CS} / \mathrm{G}$, and CTAB-CS/G (b) adsorbents. 

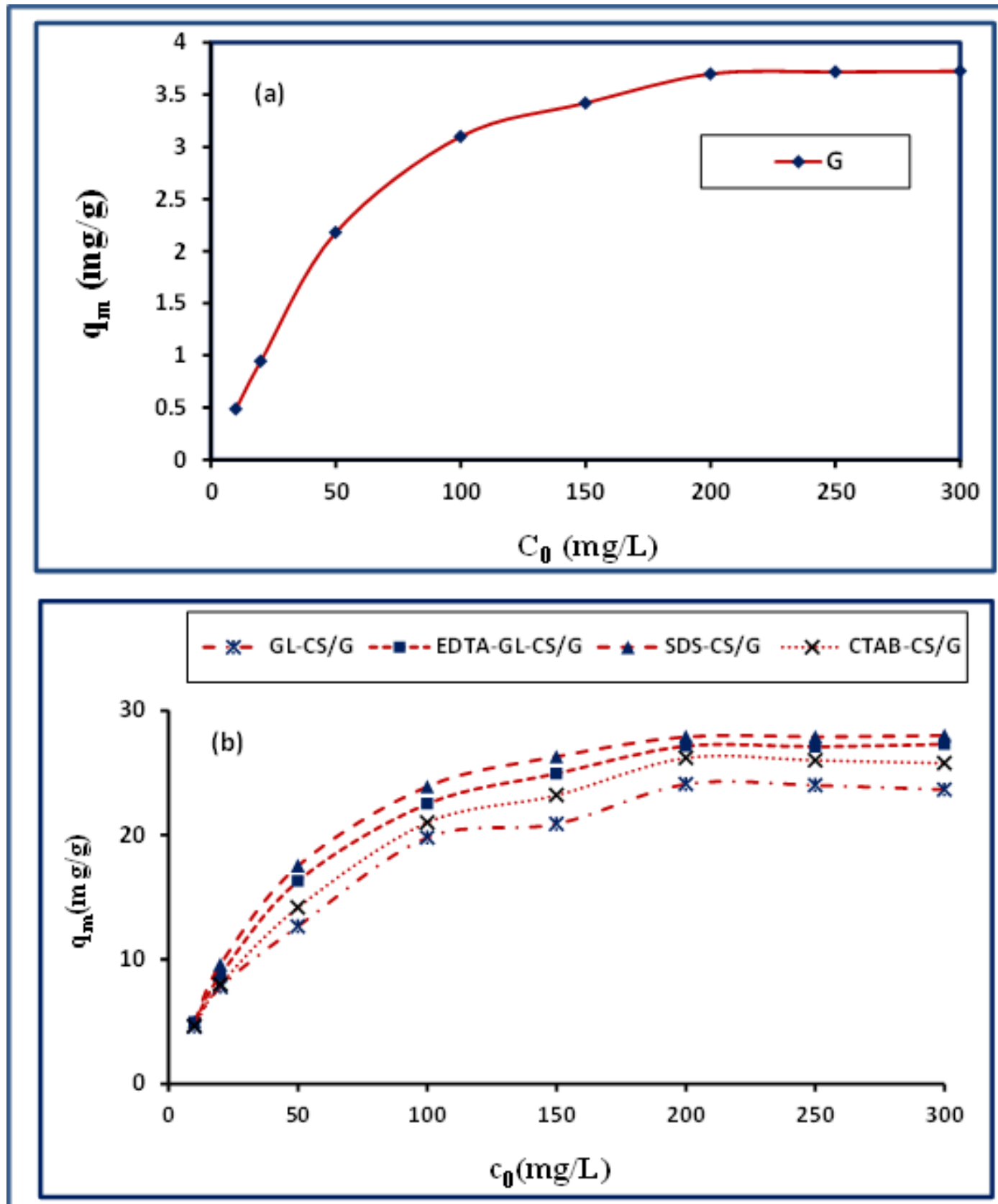

Figure 5

Influence of initial Mn(II) ions concentration on adsorption capacity of G (a); GL-CS/G, EDTA-GL-CS/G, SDS-CS/G, and CTAB-CS/G (b) adsorbents. 


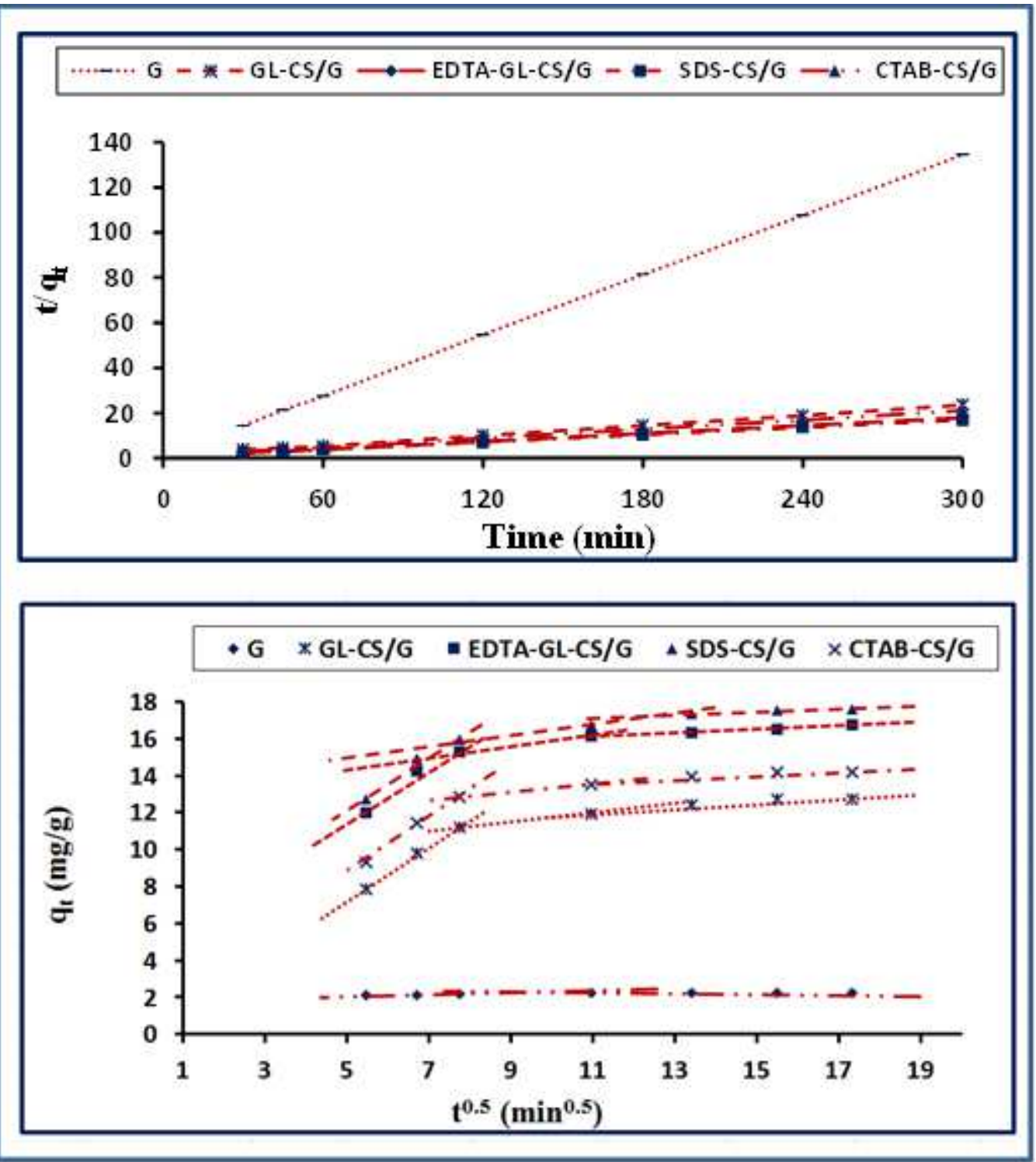

Figure 6

Pseudo-second-order kinetic model (a), and validation of intra-particle-diffusion model (b) for Mn(II) ions adsorption onto G, GL-CS/G, EDTA-GL-CS/G, SDS-CS/G, and CTAB-CS/G adsorbents. 


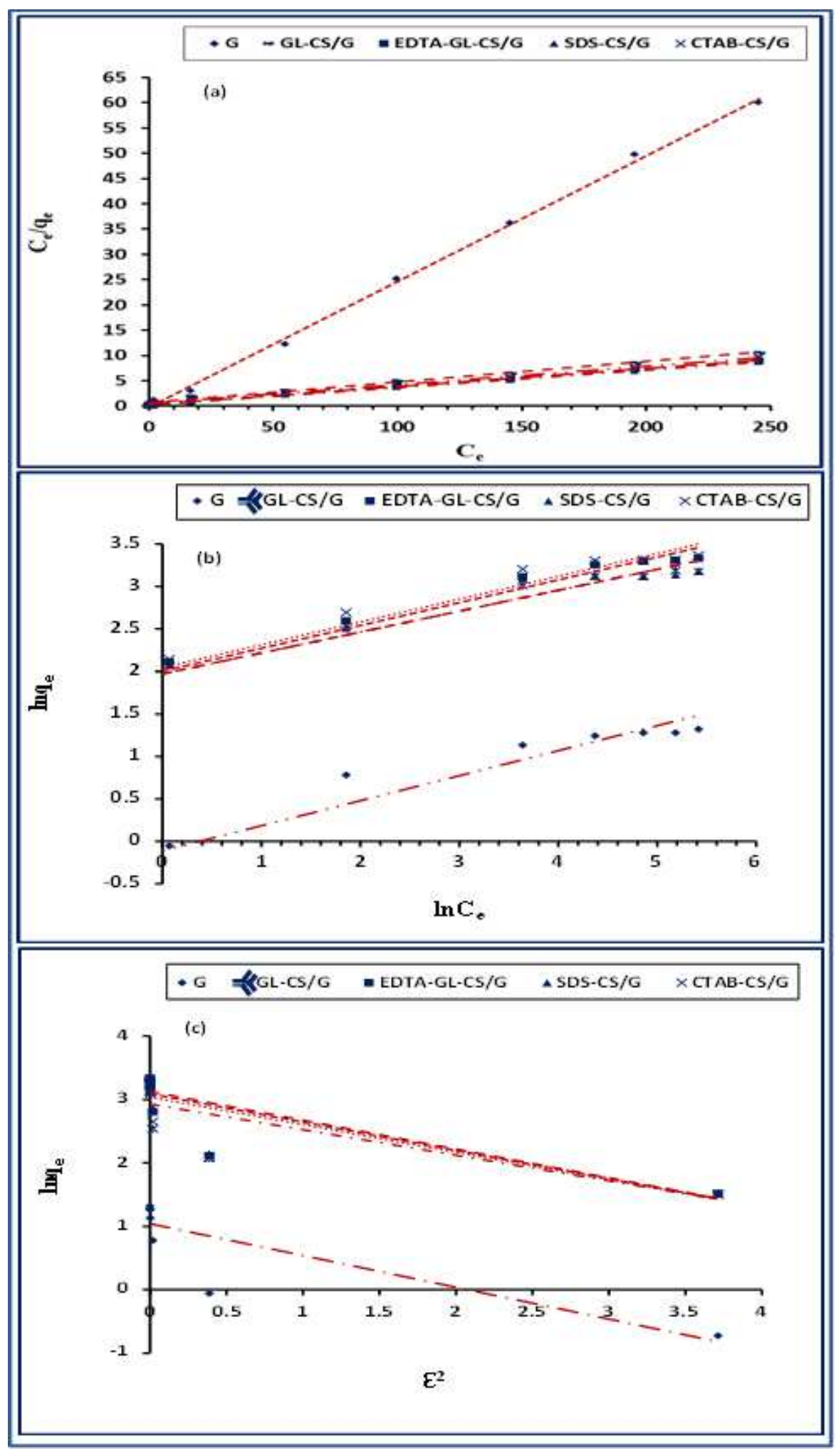

Figure 7

Adsorption isotherms of $\mathrm{Mn}$ (II) ions onto G, GL-CS/G, EDTA-GL-CS/G, SDS-CS/G, and CTAB-CS/G adsorbents: Langmuir (a), Freundlich (b), and Dubinin-Radushkevich (c). 


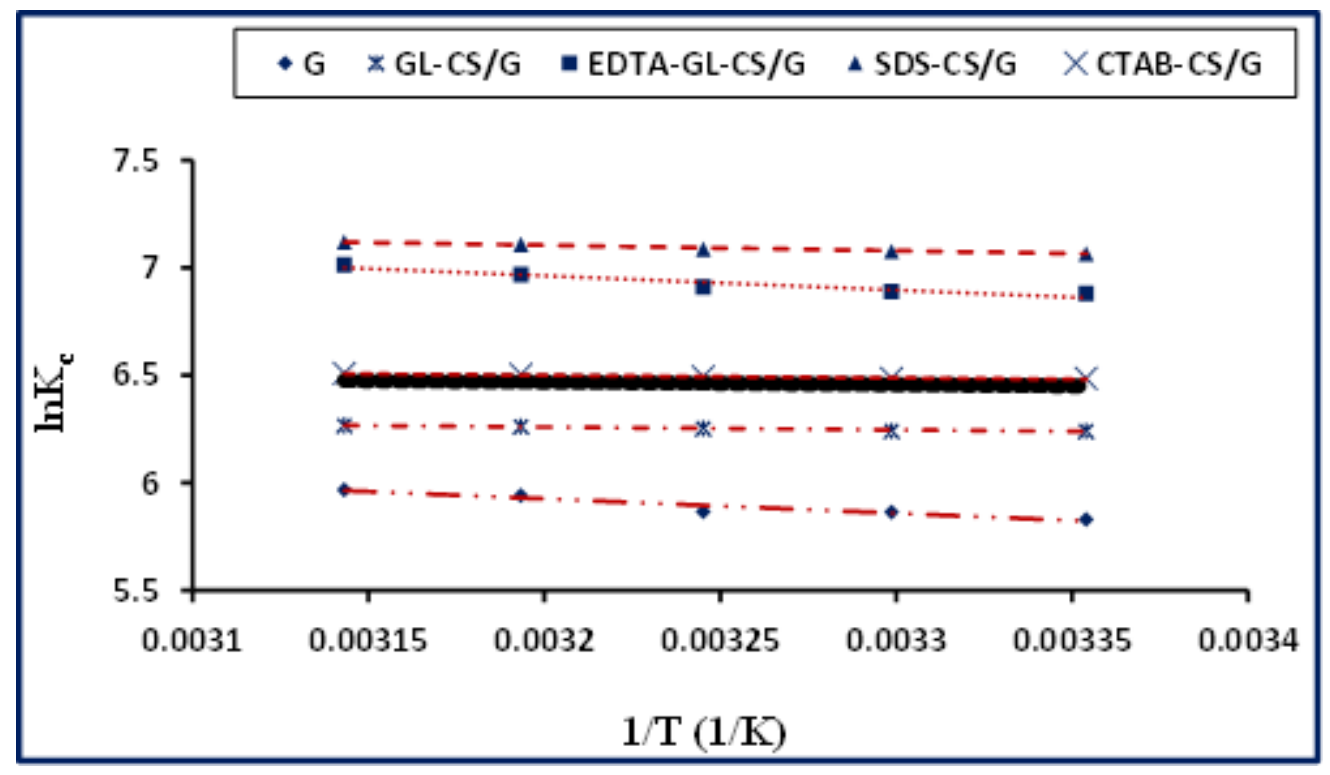

Figure 8

The plots of InKC versus 1/T for Mn(II) ions removal using G, GL-CS/G, EDTA-GL-CS/G, SDS-CS/G, and CTAB-CS/G adsorbents

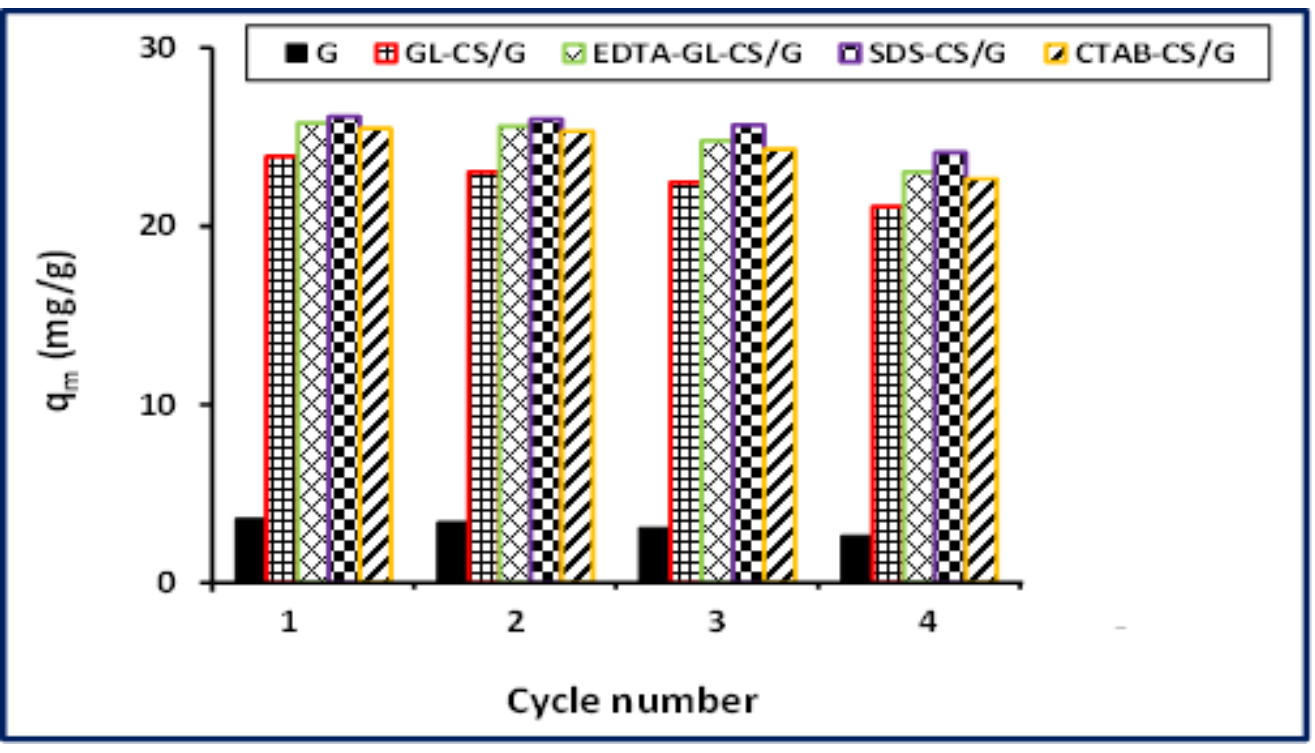

Figure 9

Regeneration efficiency of G, GL-CS/G, EDTA-GL-CS/G, SDS-CS/G, and CTAB-CS/G adsorbents for Mn(II) ion adsorption from aqueous media.

\section{Supplementary Files}

This is a list of supplementary files associated with this preprint. Click to download.

- Scheme01.png 
- GA.png 